\title{
MEDEDEELINGEN OMTRENT DE ALFOERSCHE TAAL VAN NOORD-OOST CELEBES.
}

\author{
sor \\ I. Verget.IJKENDE WOORDENI.IJST.
}

Inleiding.

Deze woordenlijst bevat een aantal woorden uit verschillende dialecten der Minahasa en uit de taal van het aangrenzend Bolaäng Mongondou. $\mathrm{Z}_{\mathrm{ij}}$ is, wat de dialecten, der Toumbulu en Toumpakěwa en het Bolaäng Mongondousch betreft, door de zendelingen 'Wilken en Schwartz opgemaakt.' Het Toumbulusch of dialect van den stam der Toumbulu wordt gesproken in de districten 'Tomohon, Sarongsong, Tombariri, Aris, Kĕlabat bawah, Kakaskassĕn en een gedeelte van Nĕgĕri baharu, dat der Toumpakěwa in de districten Toumpasso, Kawangkoan, Sonder, Tombassian, Kumoong en een gedeelte van Langowan. Het Tounseasch is het dialect van den stam der Tounsea, die de districten Tounsea, Kělabat atas en Likupang bewoont, de woorden van dit dialect leverde de zendeling Tendeloo. Het Tondanosch, de taal van den stam der Toulour, behoort te huis in de districten Tondano Toulian, Tondano Toulimambot, Rĕmbokĕn en Kakas. De heer Rooker, zendeling te Tondano, leverde het hierop betrekkelijk gedeelte der woordenlijst. De woorden der drie overige dialecten, nl. die in de districten Tonsawang, in Ratahan met Pasan (die vroeger slechts éen district, Bentěnang genaamd, uitmaakten) en in Ponosakan gesproken worden, zijn wij aan den zendeling Wiersma te Ratahan verschuldigd. 1 Overigens is nog op te merken dat onze oeklank

1 Zie Graafland, De Minahassa, Rotterdam 1866, blz. 200 vg. en 225. Bijdragen tot de kennis der Alfoersche taal in de Minahasa, uitgegeven door het bestuur van het Nederlandsch zendelinggenootschap, Rotterdam 1866 , pag. 39 vgg. en 111.

3e Volgr. IV. 
overal door $u$ is wedergegeven. Het is misschien niet overbodig de literatuur over het Alfoersch van $\mathbf{N}$. Celebes hier kortelijk te vermelden. De eerste gedrukte text in die taa! was een vrangboekje, door den zendeling Mattern in 1841 op de pers te Tomohon gedrukt. In hetzelfde jaar gaf P. P. Roorda van Eysinga in zijn Handboek der Land- en Volkenk. v. N. I. dl. I p. 227-243 iets over de spraakkunst en een woordenlijstje van de taal der Alfoeren, benevens eene vertaling van het Onze Vader, de 10 geboden en de 12 geloofsartikelen in een daar ongenoemd dialect, dat later gebleken is het Toumbulusche te zijn, vermengd met eenige woorden uit andere dialecten. In het 6 e deel van het tijdschrift van het Bat. Genootschap vindt men eenige proeven van Alfoersche poezij. In het 14,e deel van hetzelfde tijdschrift komen eenige formulen voor, die bij eedsaflegging en ordalien gebruikelijk zijn, medegedeeld door den'. heer J. F. Riedel, assistent-resident van Gorontalo. Een aantal formuliergebeden vindt men ook in het 7e deel der Mededeelingen van het Nederl. zendelinggenootschap, medegedeeld door den zendeling Wilken. Dezelfde leverde ook de bouwstoffen voor de Bijdragen tot de kennis der Alfoersche taal in de Minahasa, in 1866 door den ondergeteekende op verzoek van het bestuur van het Nederlandsch zendelinggenootschap uitgegeven, die eenige fabelen en legenden en eene schets der grammatica bevatten. Al het genoemde heeft betrekking op het dialect der Toumbulu. In dat der Toumpakěwa verschenen: een catechiseerboekje met Mal. vertaling getiteld: Pĕngadjaran agama mesehhi jang pendekh. Batavia 1868 en eene vertaling van het Evangelie van Mattheus door den zendeling Herrmann, Amsterdam 1852. Andere dialecten der Minahasa hebben wij tot dusver alleen door de belangrijke bijdragen van den heer J. F. Riedel eenigzins nader leeren kennen. In het $\mathbf{1 7}$ deel van het tijdschrift van het Batav. Genootschap gaf hij namelijk: eene Bantiksche legende in het oorspronkelijk met Nederlandsche vertaling en eenige fabelen in het dialect der Tounsea, text en vertaling. In de bekentenis van een Holontaloschen Ponggoh in hetzelfde deel leverde hij eene proeve van de taal, in een gedeelte der Gorontalosche landschappen in gebruik. Als bijdrage tot de kennis der taal van Bolaäng Mongondou zijn vooral niet te vergeten de schets der grammatica van die taal en de texten daarin, door de heeren Wilken en Schwartz uitgegeven in het 11 deel der Mededeelingen van het Nederl. Zendelinggenootschap. - Woor- 
denlijsten zijn voorts te vinden bij Raffles Hist. of Java, dl. II der uitgave in 4\%. nl. van het Alfoersch van Menado en Gorontalo; bij Dumont d'Urville Voyage de l'Astrolabe. Philologie. T. Il 193 vgg.; v. d. Crab, De Moluksche eilanden, Batavia 1862 , waar eene woordenlijst van drie Minahasische dialecten voorkomt en in het Tijdschrift v. h. Bat. Genootschap dl. IV eene vergelijkende woordenlijst van talen en dialecten in de residentie Menado, door A. J. F. Jausen. Ook in Röttger's Briefe über Hinterindien, Berlin 1844 p, 137 vindt men iets over het Alfoersch der Minahasa, en in de Mededeelingen van het Nederl. Zendel. dl. VI eene proeve van oud-Alfoersch teekenschrift en in dl. VII eene poging tot verklaring daarvan door Ds. Tiele. Eene woordenlijst van de taal der Gorontalezen en van de Togean eilanden gaf C. B. H. van Rosenberg achter zijne Reistogten in de afdeeling Gorontalo, Amst. 1865.

In de woordenlijst, toegevoegd aan het werk van A. R. Wallace The Malay Archipelago London 1869, zijn ook eenige woorden opgenomen uit het Alfoersch der Minahasa en van Bolang itam.

G. K. Nibmann. 


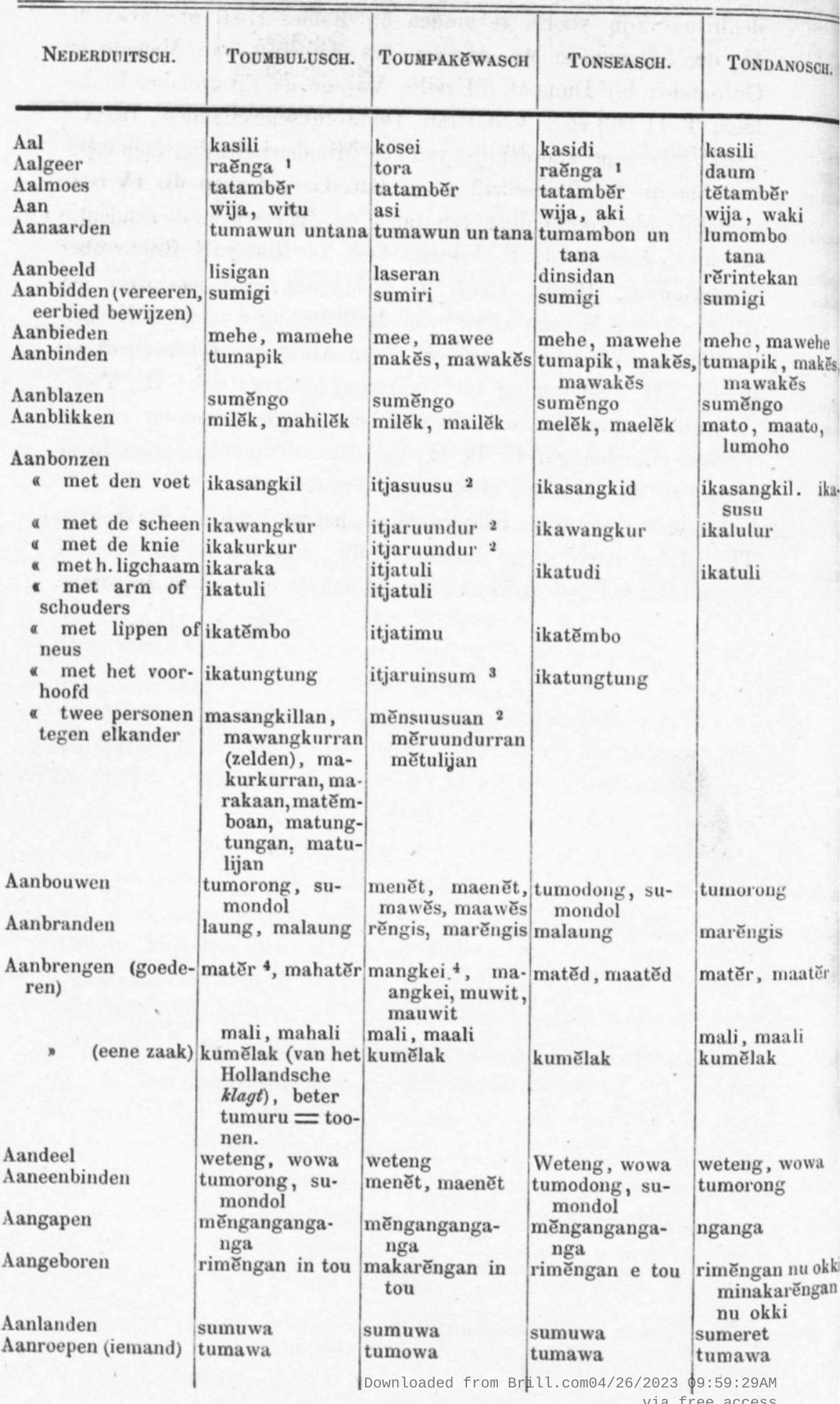




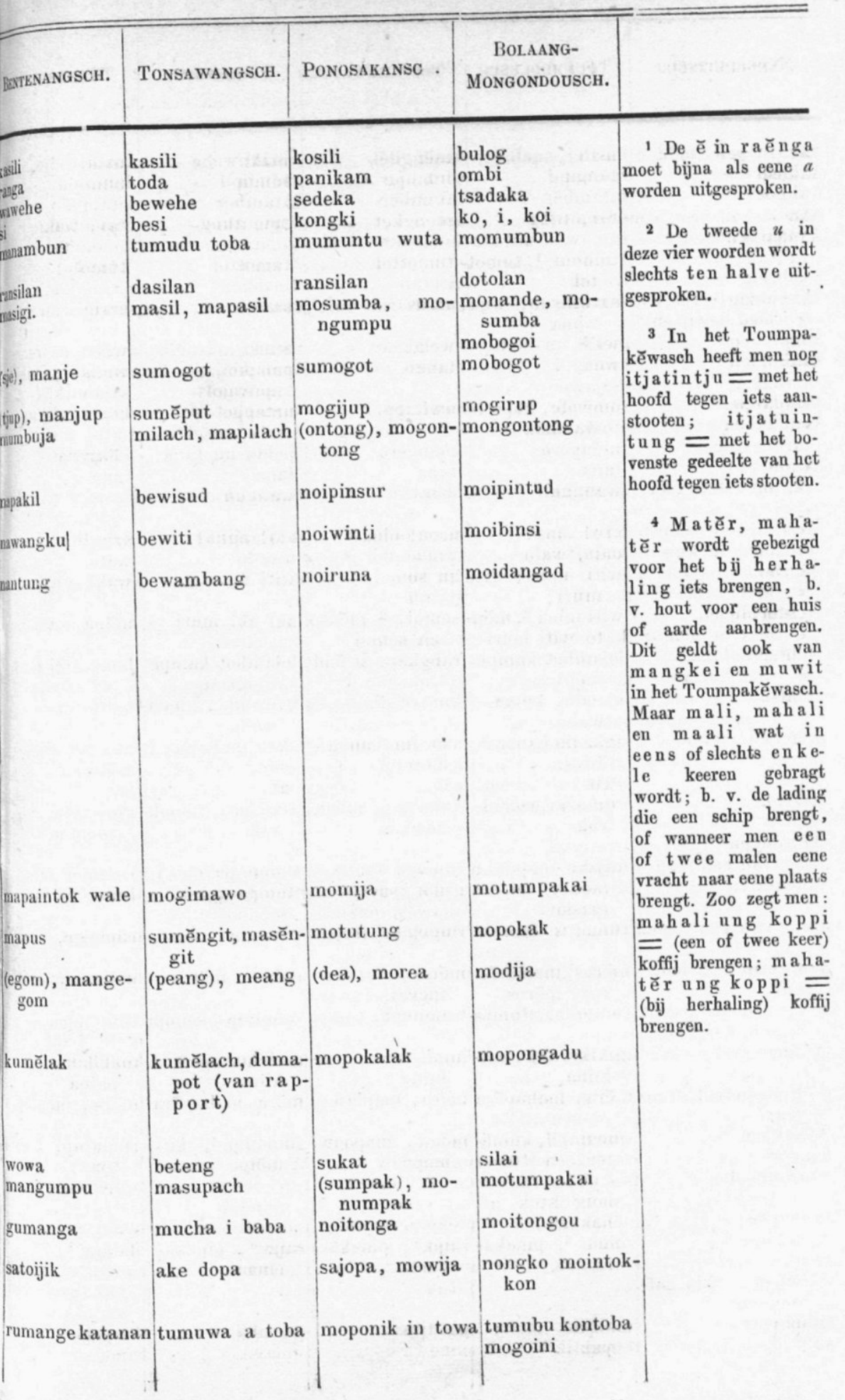




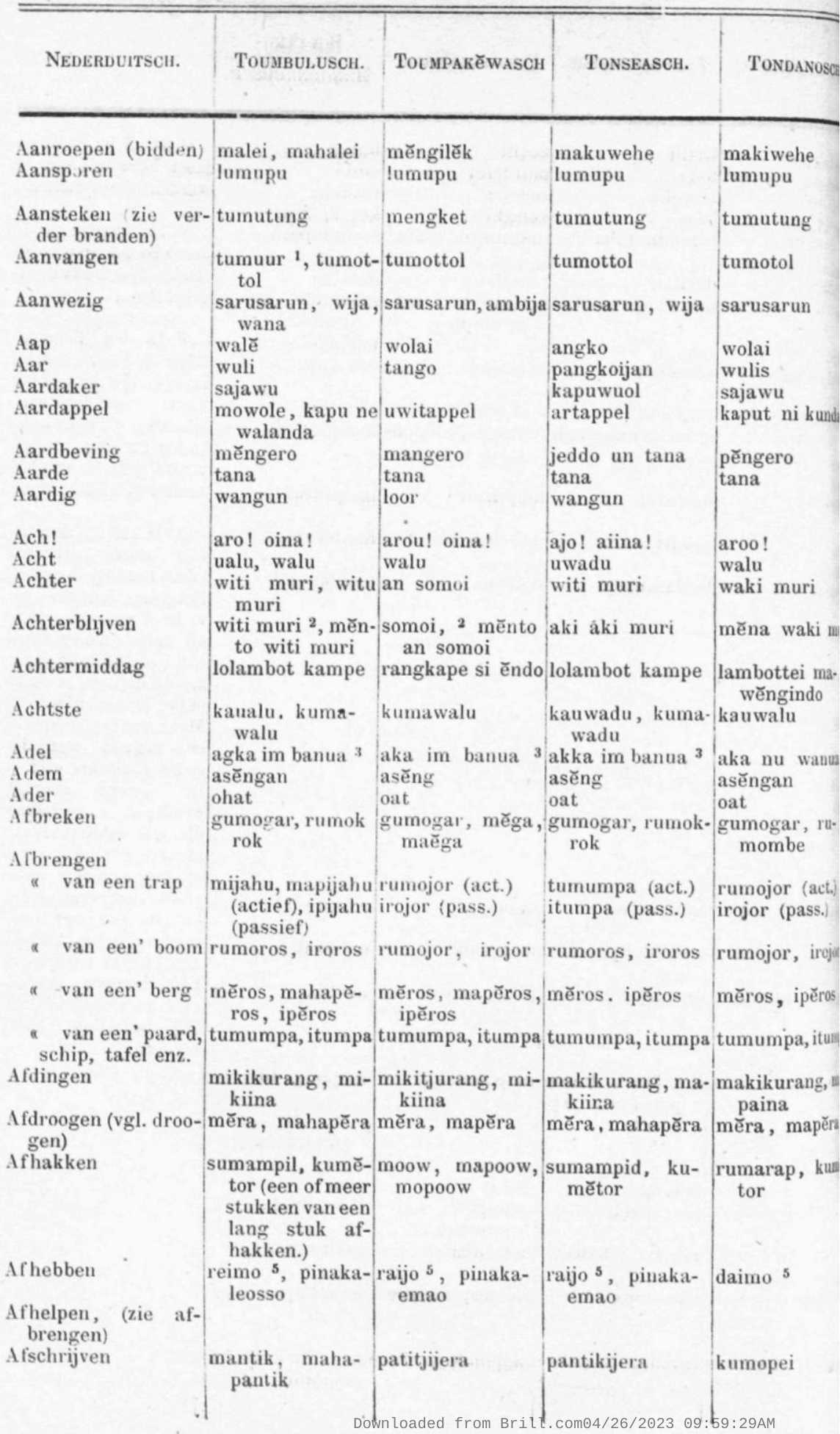




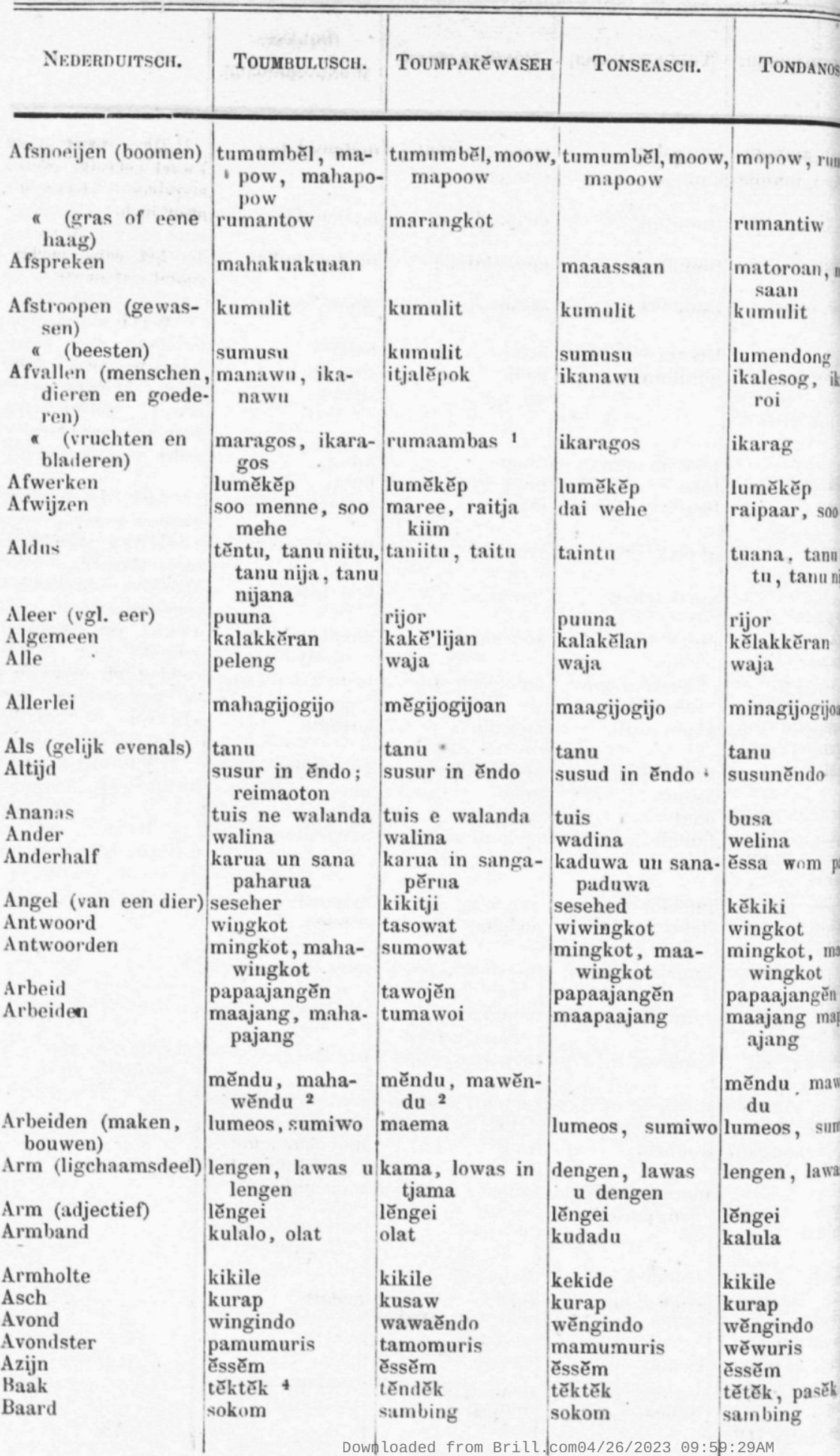




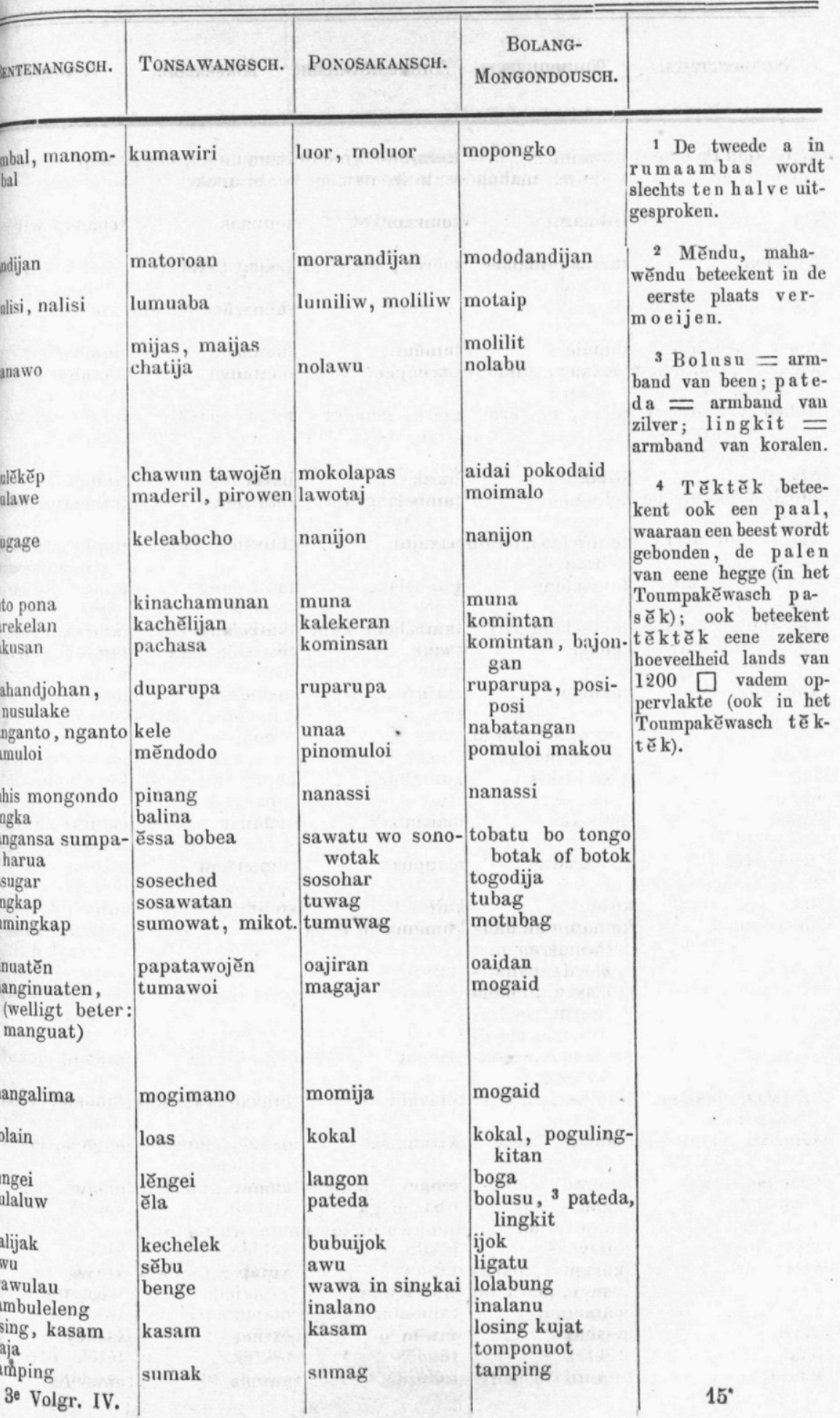




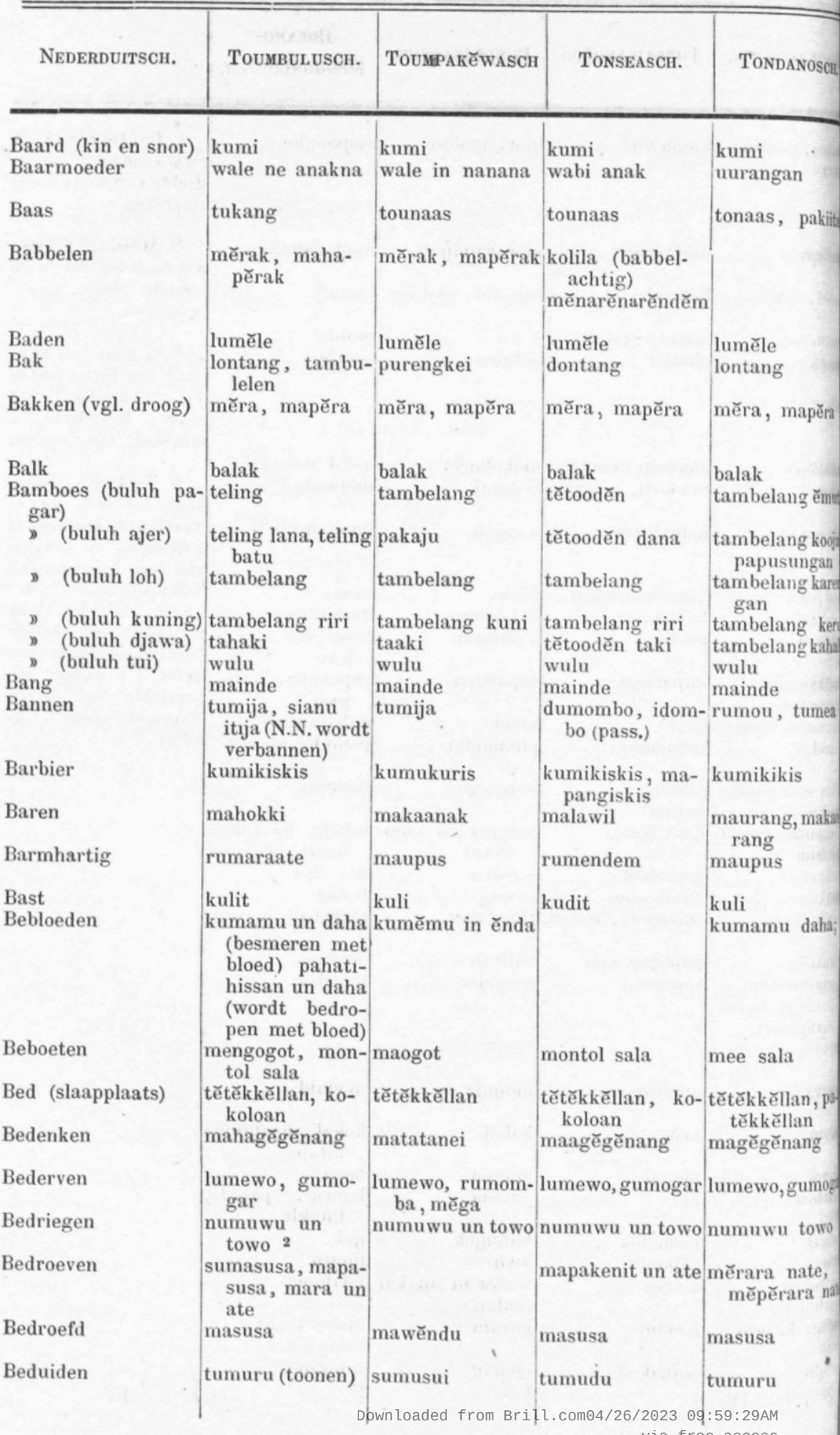




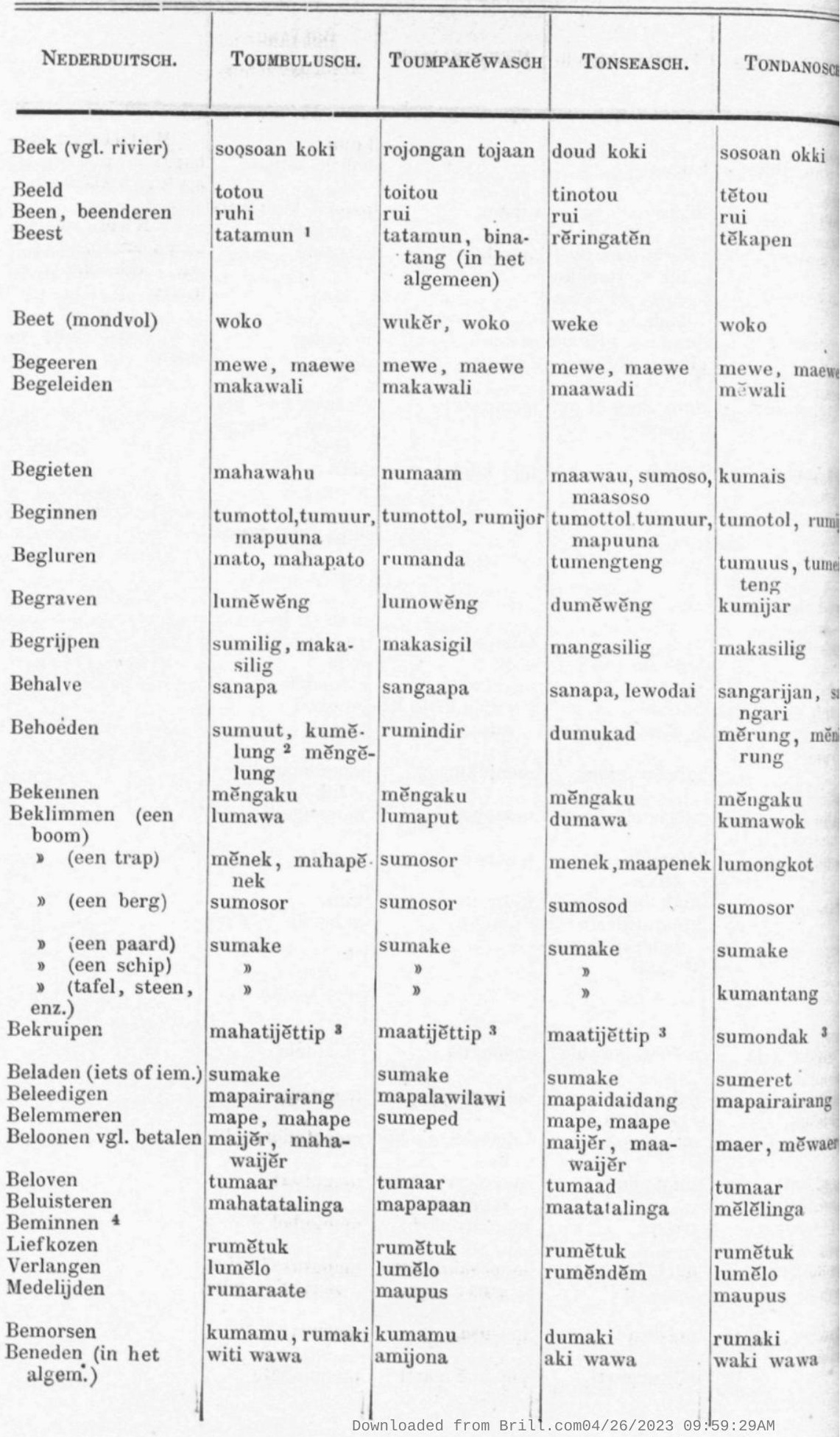




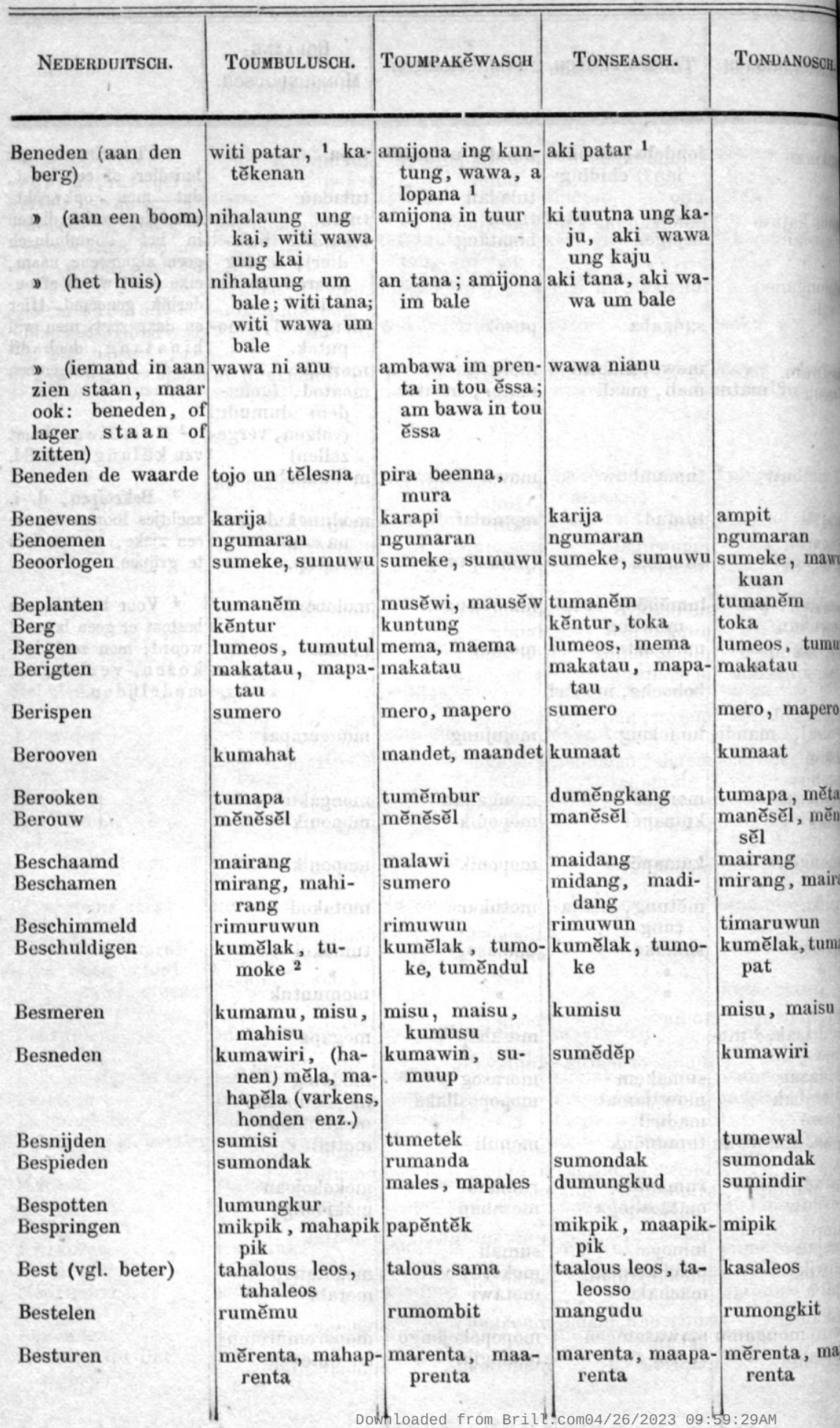




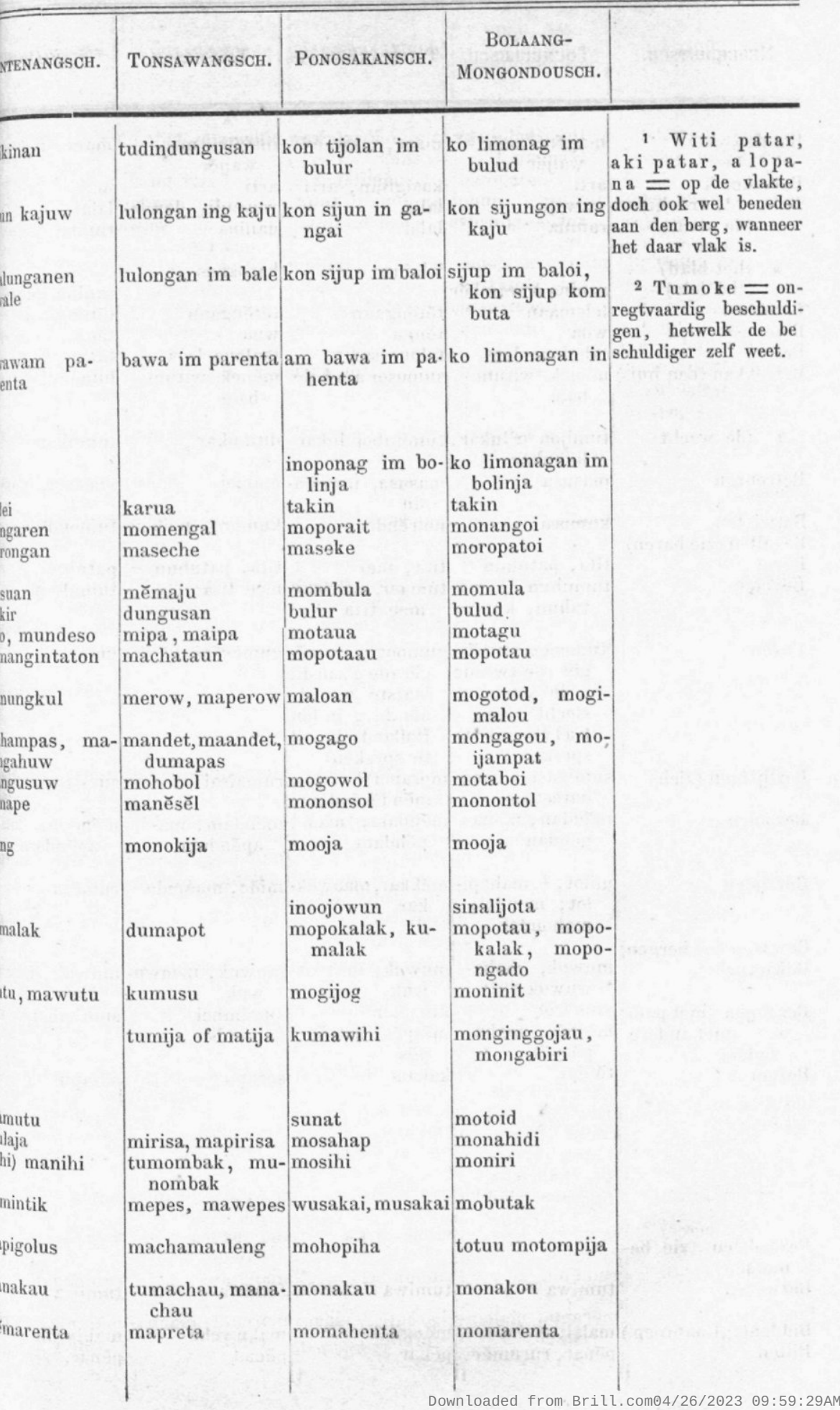




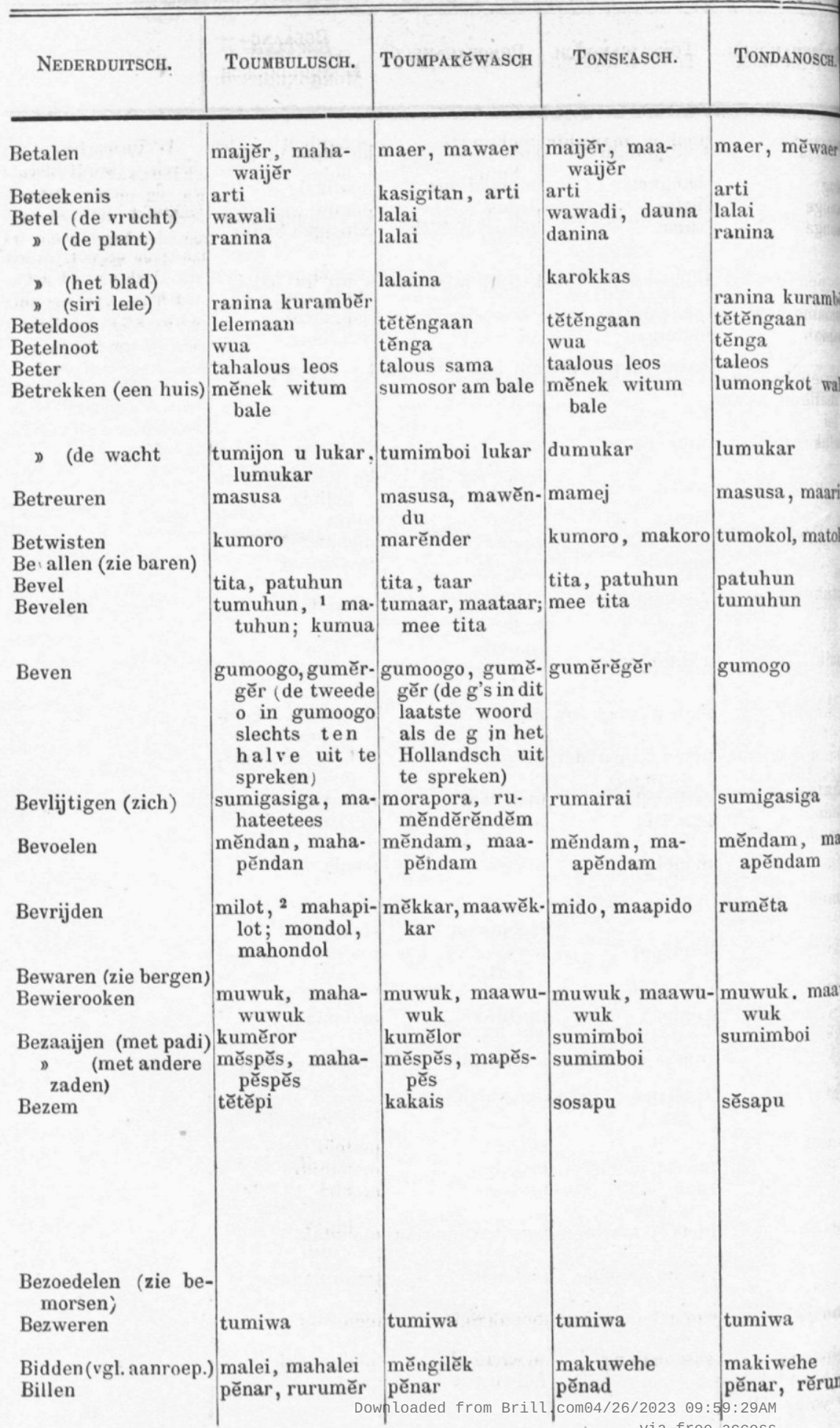




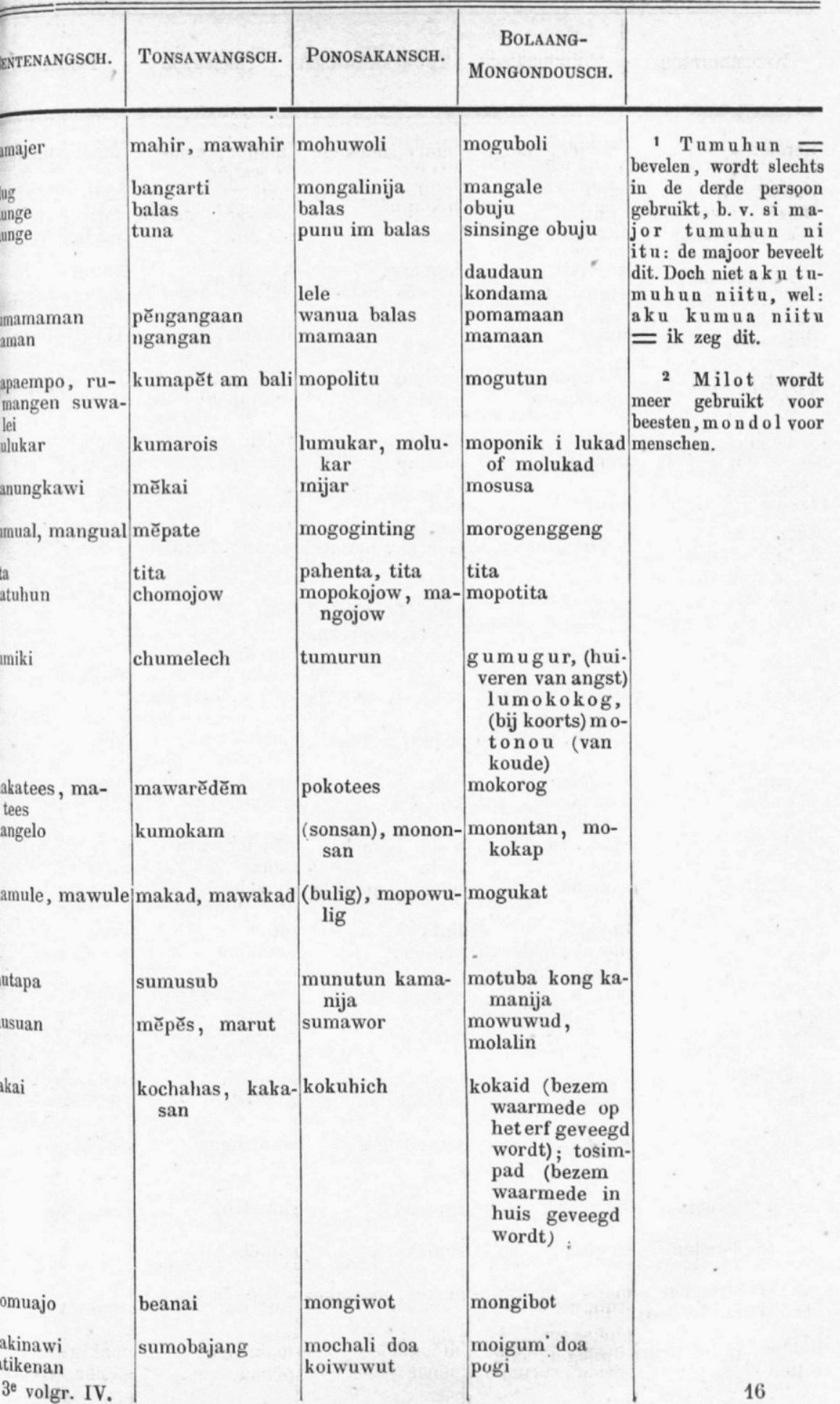




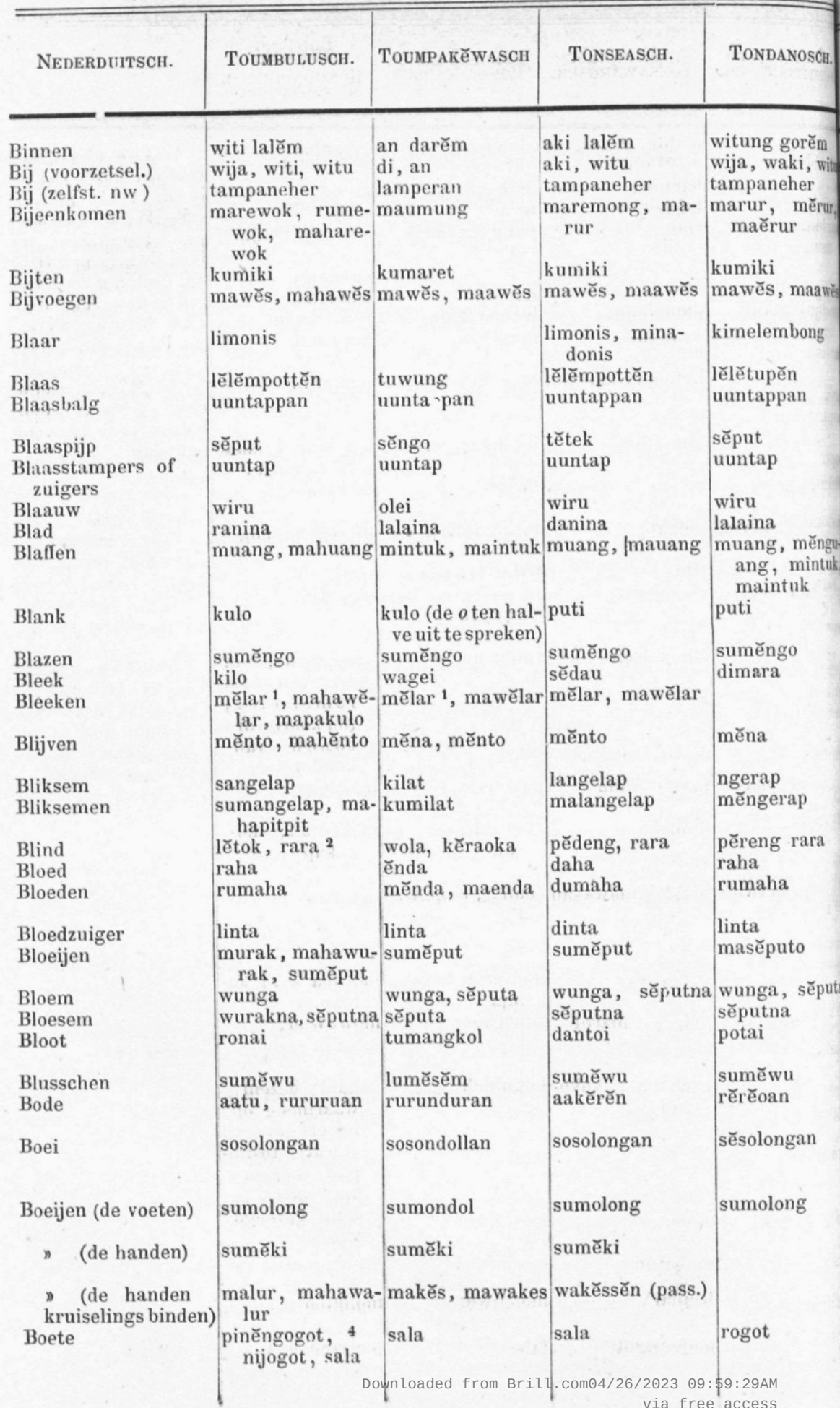




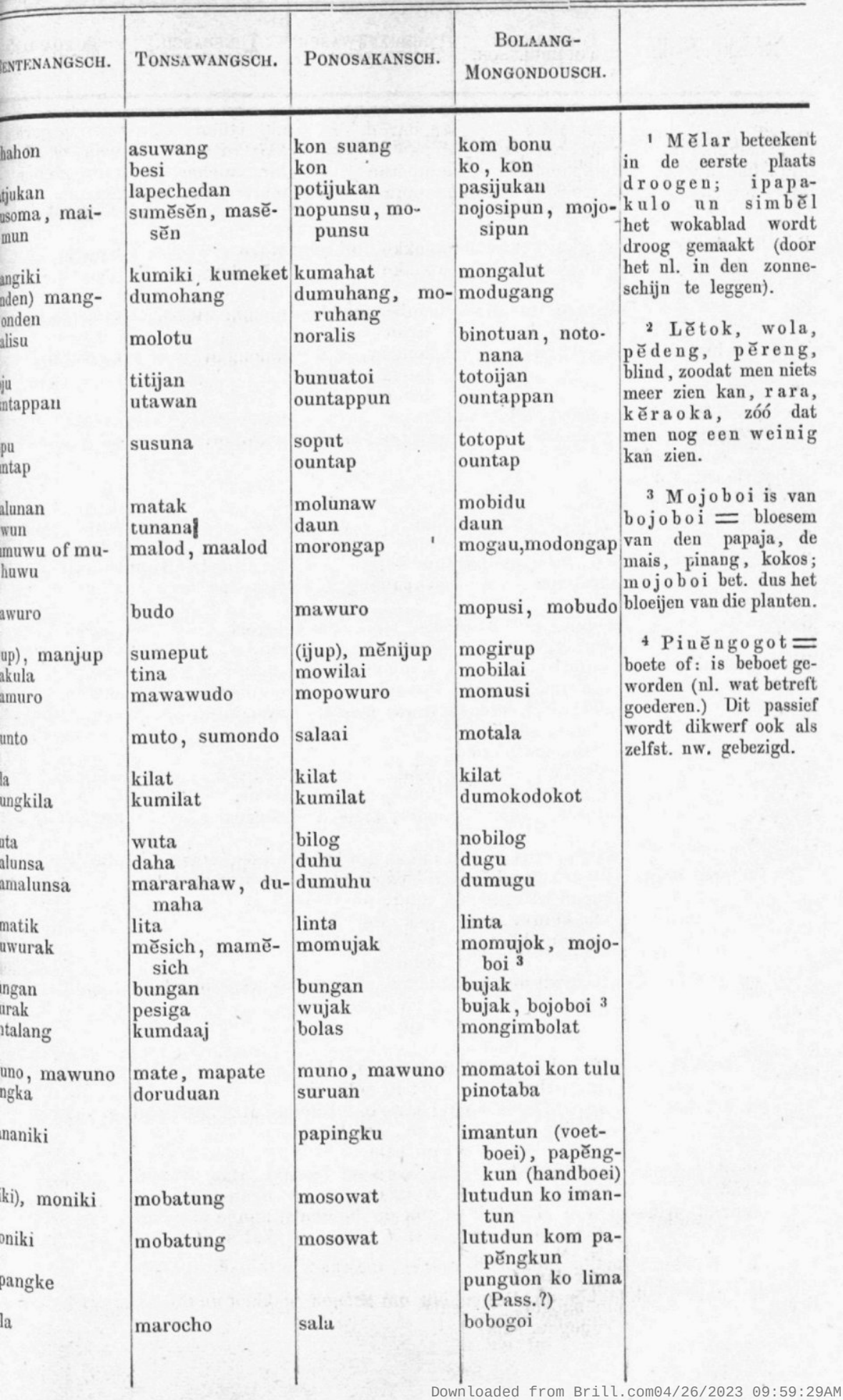




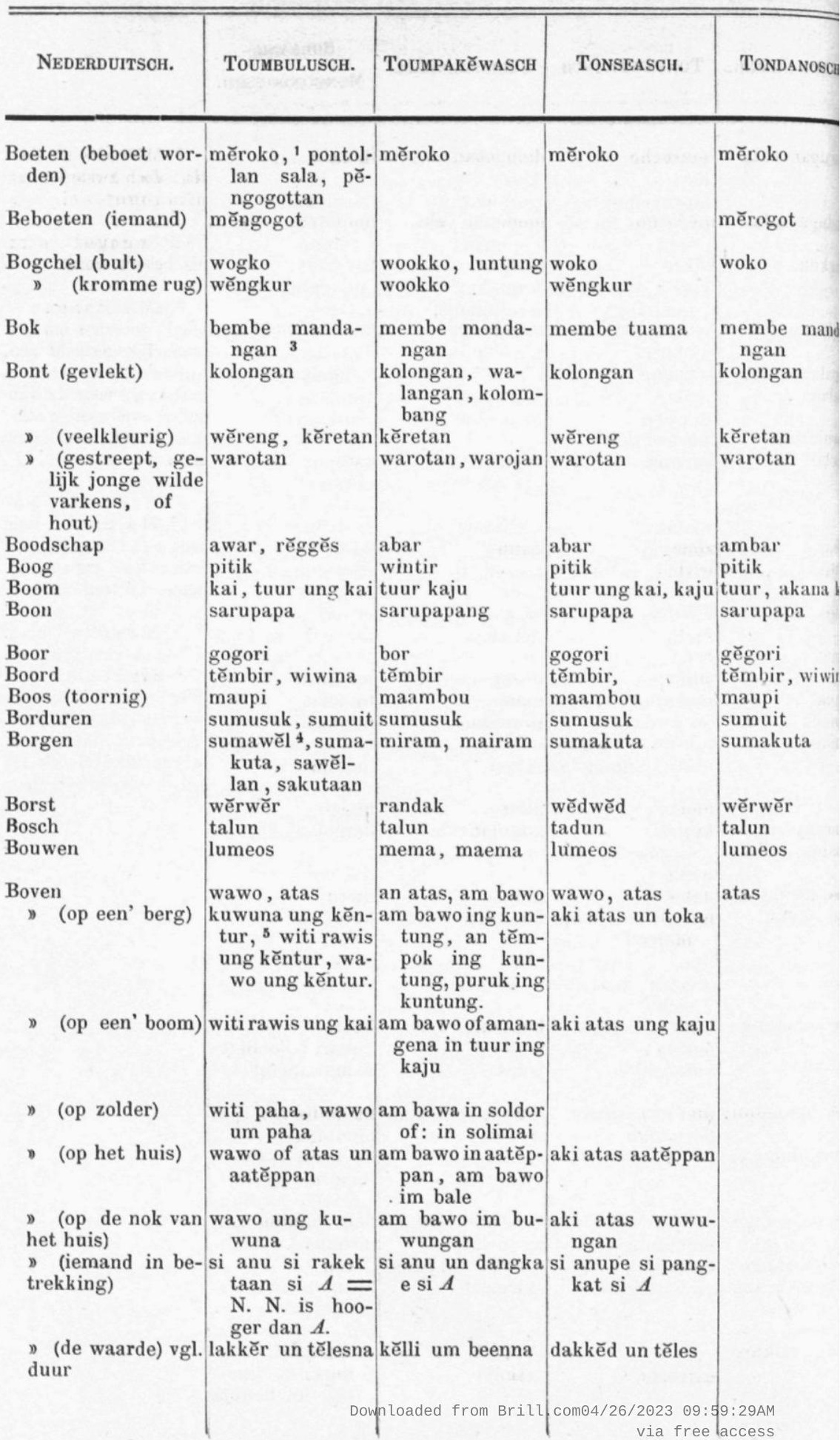




\begin{tabular}{|c|c|c|c|c|}
\hline Nederduitsch. & Toumbulusch. & TOLMPAKӗWASCH & Tonseasch. & Tondanosch: \\
\hline Braaf & leos & sama & leos & leos \\
\hline Braden (vgl. bakken) & měra, mahapěra & mẽra, mapěra & mẽra, mapěra & měra, mapě \\
\hline Braken & lumua & lumua & dumua & kuměro \\
\hline $\begin{array}{l}\text { Branden (in br. raken } \\
\text { of staan) }\end{array}$ & malaung & malaung & malaung & marengis \\
\hline $\begin{array}{l}\text { (aansteken een } \\
\text { lamp, kanokano } \\
\text { enz.) }\end{array}$ & tumutung & $\begin{array}{l}\text { mengkět, rumi- } \\
\text { tjet }\end{array}$ & tumutung & tumutung \\
\hline $\begin{array}{l}\text { (vuur aanmaken } \\
\text { in keuken of elders) }\end{array}$ & rumiket & $\begin{array}{l}\text { mengkět, rumi- } \\
\text { tjet }\end{array}$ & rumiket & tumou api \\
\hline b (een huis) & lumaung & lumaung & lumaung & ruměngis \\
\hline ) (vlammen) & lumajas & maẽmbung & rumambun & \\
\hline Brandhout & lungu, 1 pinijas & kaju 1, pinijas & dungu 1, pinijas & lungu \\
\hline Breed & lëmpar & wělar, lĕmpar & dĕmpad & pĕnar \\
\hline $\begin{array}{l}\text { Brein } \\
\text { Breken } 2\end{array}$ & & $\begin{array}{l}\text { ngaas } \\
\text { lumentu }\end{array}$ & $\begin{array}{l}\text { utēk } \\
\text { rumẽpu, maarěpu }\end{array}$ & $\begin{array}{l}\text { utêk } \\
\text { rumĕpu }\end{array}$ \\
\hline 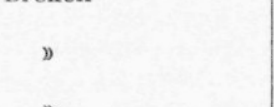 & $\begin{array}{l}\text { rẽpu } \\
\text { suměmpo, maha- } \\
\text { sẽmpo }\end{array}$ & sumēmpo & $\begin{array}{l}\text { suměmpo, ma- } \\
\text { asẽmpo }\end{array}$ & sumēmpo \\
\hline ) & $\begin{array}{l}\text { tumarar, maha- } \\
\text { tarar }\end{array}$ & mēte, mapēte & měpor, maapēpor & mẽte, mapěte \\
\hline Reoleon 3 & $\begin{array}{l}\text { rumepes, maha- } \\
\text { repes }\end{array}$ & $\begin{array}{l}\text { rěmbus, ruměm- } \\
\text { bus, marěmbus }\end{array}$ & $\begin{array}{l}\text { rumangkut, ma- } \\
\text { arangkut }\end{array}$ & rumangkut \\
\hline Breken 3 & $\begin{array}{l}\text { marĕpu, masẽm- } \\
\text { po, matarar } \\
\text { marěpěs }\end{array}$ & $\begin{array}{l}\text { malěntu, masẽm-r } \\
\text { po, mapěte } \\
\text { marěmbus }\end{array}$ & $\begin{array}{l}\text { marěpu, masĕm. } \\
\text { po, mapěpor } \\
\text { marangkut }\end{array}$ & $\begin{array}{l}\text { marẽpu } \\
\text { masĕmpo } \\
\text { mapẽte } \\
\text { marangkut }\end{array}$ \\
\hline Brengen & mali, mahali & mali, maali & mawa, maawa & mali, maali \\
\hline Broeder & katuari tuama & poow tuama & katuari tuama & patuari tua \\
\hline Broeijen (vgl. zitten) & maharumĕr & lumukut & tuměkur & měrumun \\
\hline Bron & kĕmbuan un dano & lembojan in dano & $\begin{array}{l}\text { pakěmbuan un } \\
\text { dood }\end{array}$ & $\begin{array}{l}\text { gagaran, kěm } \\
\text { buan dano }\end{array}$ \\
\hline Brug & tete & tete & tete & lelembetan \\
\hline Bruid & kaleos & paromaan & si endona & kaleos \\
\hline $\begin{array}{l}\text { Bruidegom } \\
\text { Bruin }\end{array}$ & $\begin{array}{l}\text { kaleos } \\
\text { prangdangan }\end{array}$ & $\begin{array}{l}\text { maroma } \\
\text { praindangan }\end{array}$ & parundangan & $\begin{array}{l}\text { kaleos } \\
\text { meatuwa }\end{array}$ \\
\hline Buffel & kĕrwou & kĕrwou & karbou & kĕrwou \\
\hline $\begin{array}{l}\text { Buigen (iets of zich } \\
\text { achterover buigen) }\end{array}$ & rumeru & lumea, měntir & ruměko & rumēko \\
\hline $\begin{array}{l}\text { (zich voorover } \\
\text { buigen) }\end{array}$ & $\begin{array}{l}\text { mongkot, ma- } \\
\text { hongkot }\end{array}$ & kumuru & $\begin{array}{l}\text { mongkot, ma- } \\
\text { hongkot }\end{array}$ & $\begin{array}{l}\text { monghot, ma } \\
\text { kot }\end{array}$ \\
\hline $\begin{array}{l}\text { (de knie bui- } \\
\text { gen) }\end{array}$ & kumurur & kumundu & kumuru & kumurur \\
\hline $\begin{array}{l}\text { Buik } \\
\text { Buiten (het huis, op } \\
\text { het erf) }\end{array}$ & $\begin{array}{l}\text { poot } \\
\text { witi lessar }\end{array}$ & $\begin{array}{l}\text { poot, tinai } \\
\text { ang kintal }\end{array}$ & $\begin{array}{l}\text { tijan } \\
\text { aki kalassan }\end{array}$ & tijan \\
\hline $\begin{array}{l}\text { (het erf, aan de } \\
\text { andere zijde) }\end{array}$ & witi lewet & a luwar ing kin- & & \\
\hline $\begin{array}{l}\text { (het dorp, aan } \\
\text { den kant der } \\
\text { negeri) }\end{array}$ & $\begin{array}{l}\text { witi tẽmbir um } \\
\text { banua }\end{array}$ & a luwar in roong & $\begin{array}{l}\text { aki pinggir um } \\
\text { banua }\end{array}$ & \\
\hline Buskruid & uwa & $\begin{array}{l}\text { uwa } \\
\text { onnloaded from Bril }\end{array}$ & $\begin{array}{l}\text { uwa } \\
\text {. com๑4/26/2023 } \odot 9\end{array}$ & $\begin{array}{l}\text { uwa } \\
59: 29 A M\end{array}$ \\
\hline
\end{tabular}




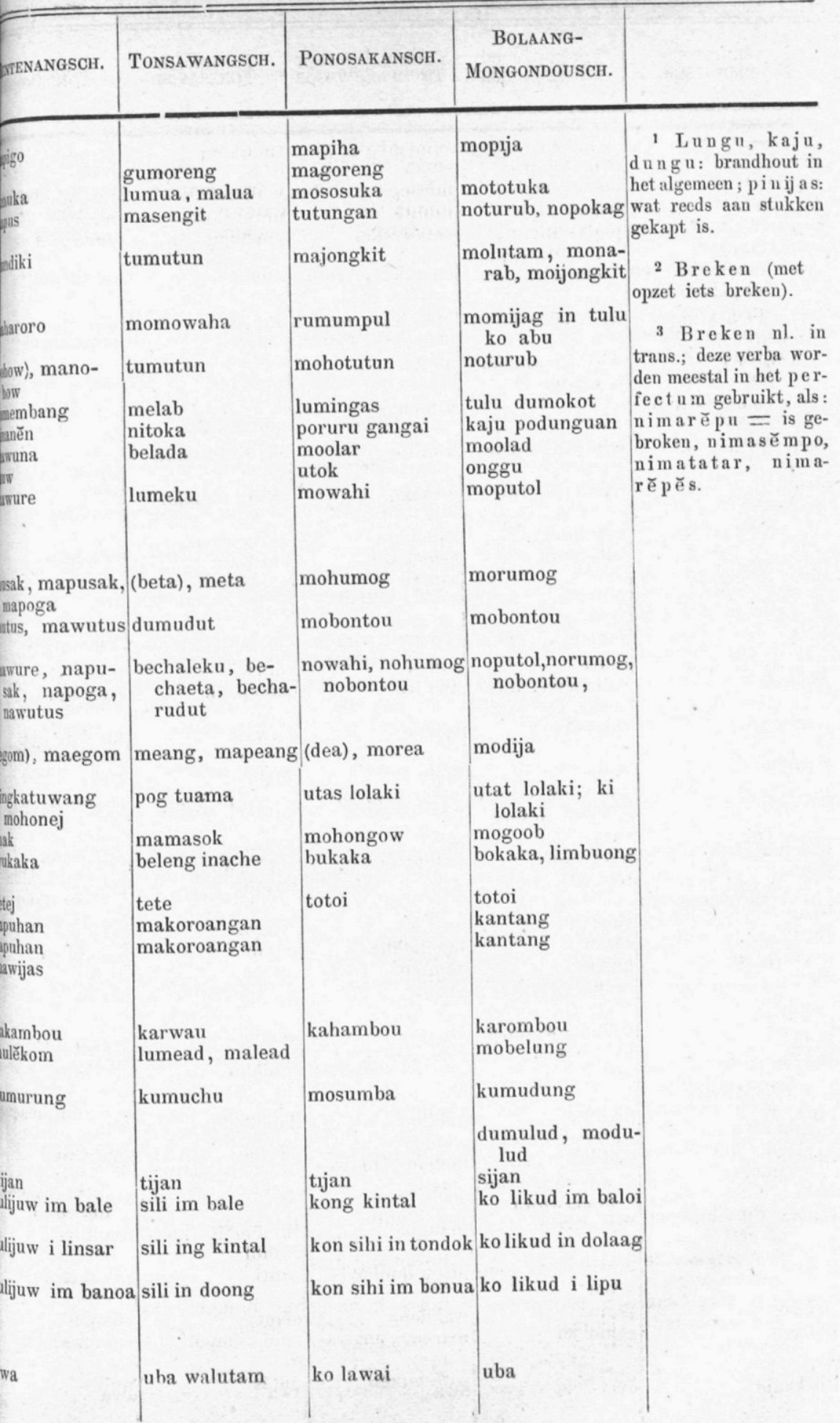




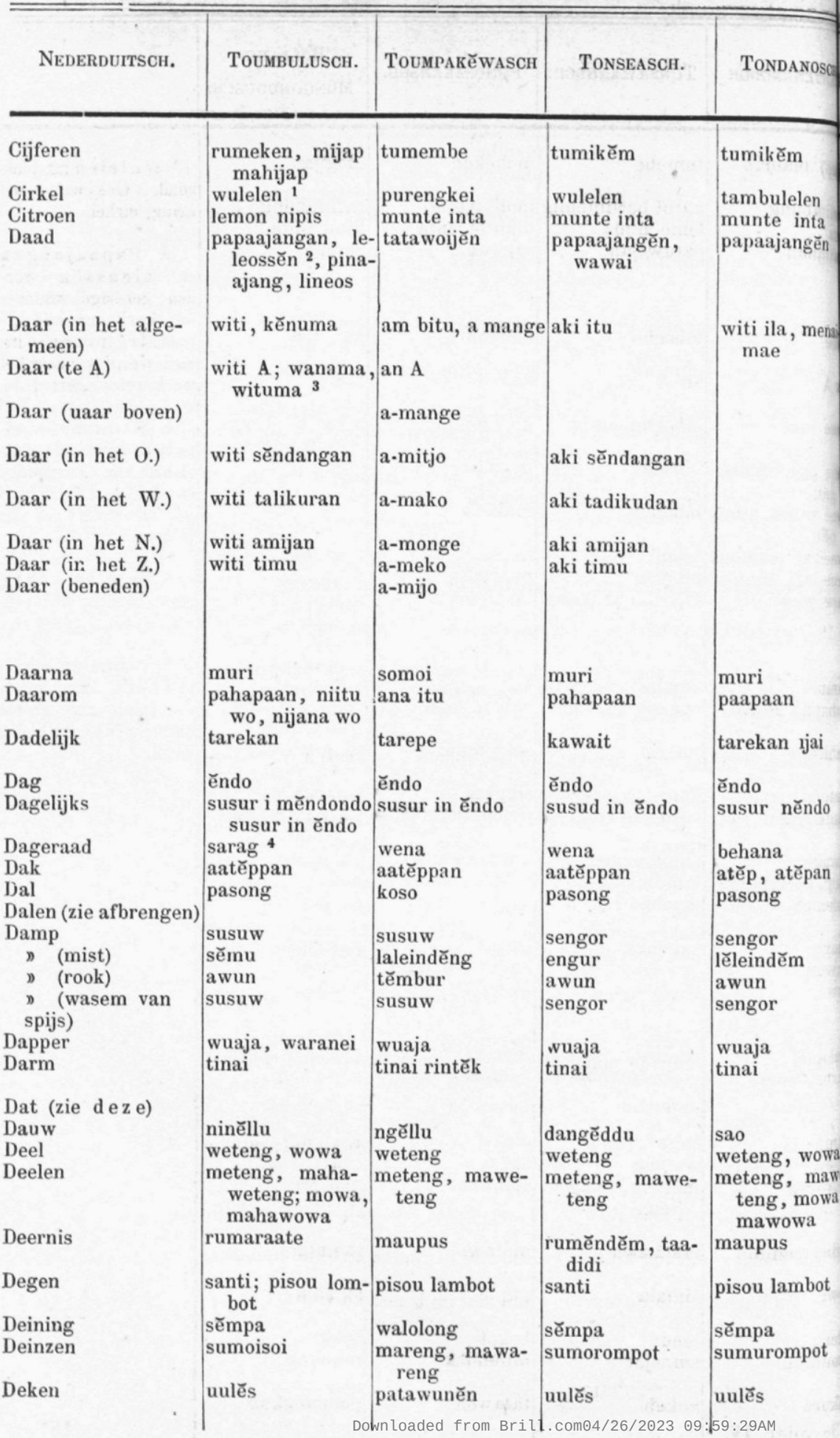




\begin{tabular}{|c|c|c|c|c|}
\hline NEDERDUITSCH. & Toumbulusch. & TOUMPAKе̌WASCH & TonsEasch. & TONDANOS \\
\hline Dekken & mulěs, mahulěs & tumawun & mulĕs, mahulěs & mulěs, m: \\
\hline Deksel & kěkělěw & kěkělěw & $\begin{array}{l}\text { kěkělěw, toto- } \\
\text { ngew }\end{array}$ & kěkělěw \\
\hline Denken & gumĕnang & rumeken & guměnang & gumĕnang \\
\hline Derde & $\begin{array}{l}\text { katěllu, kuma- } \\
\text { těllu } \\
\text { pěpěnět }\end{array}$ & $\begin{array}{l}\text { kumatěllu } \\
\text { papalěn }\end{array}$ & $\begin{array}{l}\text { katěllu, kuma- } \\
\text { těllu } \\
\text { pěpěnět }\end{array}$ & $\begin{array}{l}\text { katěllu, k } \\
\text { těllu } \\
\text { pěpalěn }\end{array}$ \\
\hline
\end{tabular}

Dewijl

Deze

pahapaan, niitu paapaan, anai, pahapaan, ni itu paapaan, jani wo, nijana wo, ana itu ja niitu

kěnu ' ${ }^{\text {, itu }}{ }^{2}$, itii ${ }^{3}$, anịo, itu, nijo, niai, itu, itii, niija, itu, ıtii, ija, ija ${ }^{4}$, ana siijai, siitu, ana

sijana

Dezelfde (als die van kĕnukan, nisıja-anijoka. isijaka, kĕnukan, nisija-nisijakan, nit vroeger, maar ook: kan, niitukan, siituka, nijasaka die of dat verloren was en wedergevonden is)

Dezelfde (juist dit en nisija, niitu, niija, isija, siitu, niija, nisija, niitu, niija, nisija, nittu, ne geen ander)

Dezelfde (dit slechts; kěnu uman, sija anijokě, sijakě, kĕnu uman, sija sija ite, itu ite niet meer dan dit, uman, itu uman, itukě, sijanakě, uman, itu uman, ite, ana ite of dan hij, zij [sija]) ija uman, ana uman

Dezelfde (dit is nog kĕnumokan,

si anịjooka, isijao kěnumokan, nisi-nisija mokan, ija uman, ana uman

kan, niitukan, kan, niijak niijakan, nija- nijanakan. nakan nijana $\quad$ nijana slechts overgeble- nisijamokan, ven, hetander is op; niitumokan, of: hij, zij is over- niijamokan, gebleven, de anderen zijn vertrokken)

Dichtstuk

Dief nijanamokan

ka, siituoka, jamokan, nijasiijaoka. sijana- namokan oka

raranin

nanain tatambakĕn marěmu, tarě- marombit muĕn 5

Diefstal

Dienaar

") (slaaf)

Dienen

Dienstig

Diep

Dieplood

Dier (zie beest)

Digt (van lijnwaad) iměk

Digt (van rijst op het indět, kiměr veld)

Digt (van ander kimĕr plantsoen)

Digt (van planken, riněp welke naauwsluitend aan elkander zijn geschikt)

Digt (van aarde, hout)

Digtbij

\section{riněmu ${ }^{6}$}

maopo

ata

maopo

maopo
makaleos 7 , bĕr-katuang

guna

rarĕm

kimĕr

rinĕp

rimat

leler, tawi

rinombit

matuang

ata

rarěm

patonton

rimat

rimat

kětěp

tawi maopo

pinangudu

\section{maopo}

rimat, iměk

rimat, iměk makaleos, běr-

itumokan, ijamokan, namokan

tětambakĕn rongkit, rum kit

rinongkit

maopo

ata

maopo

kalooran

rarěm, urĕp

watu tětoro

rarěm

patonton

rimat, indět

rimat 


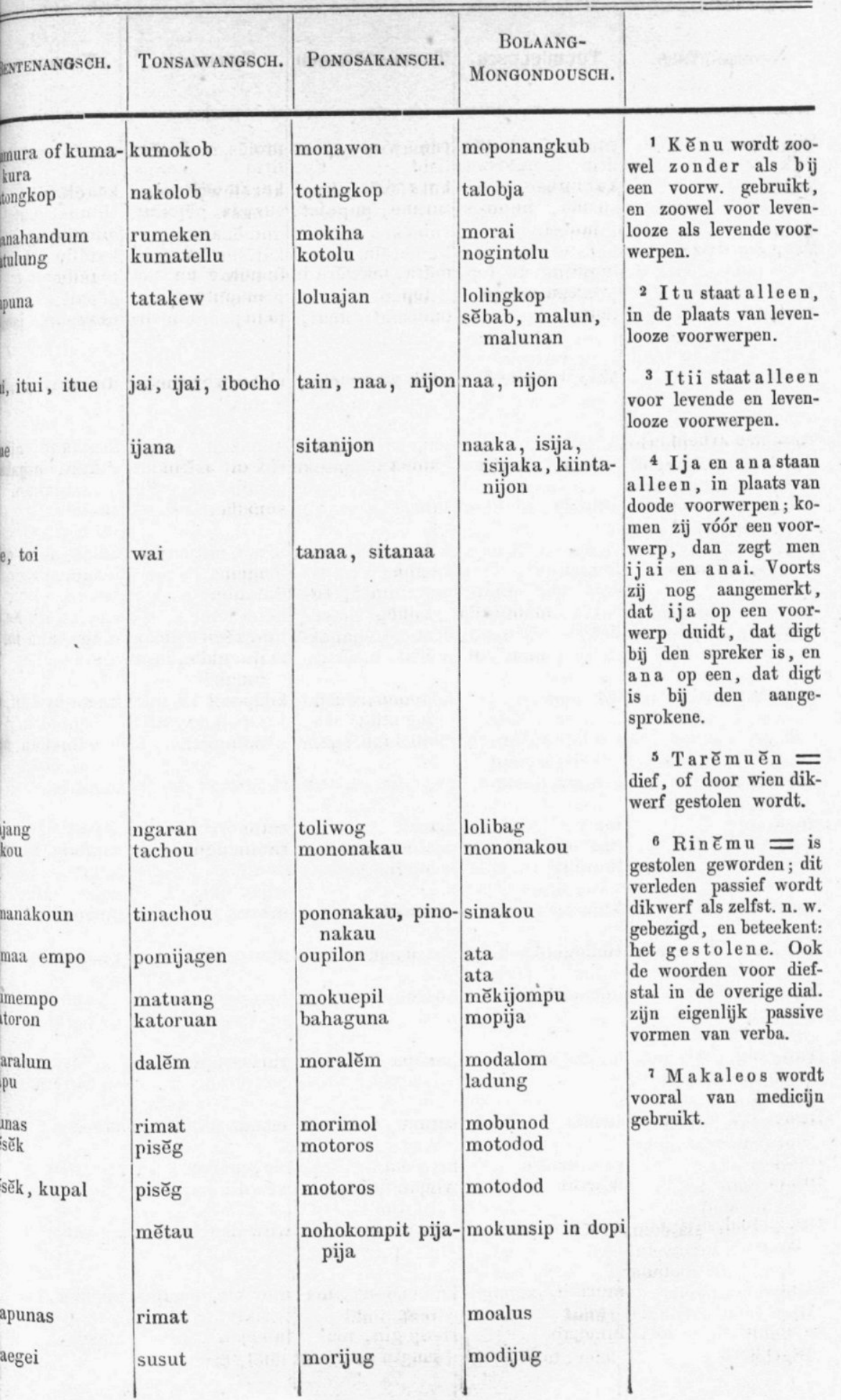




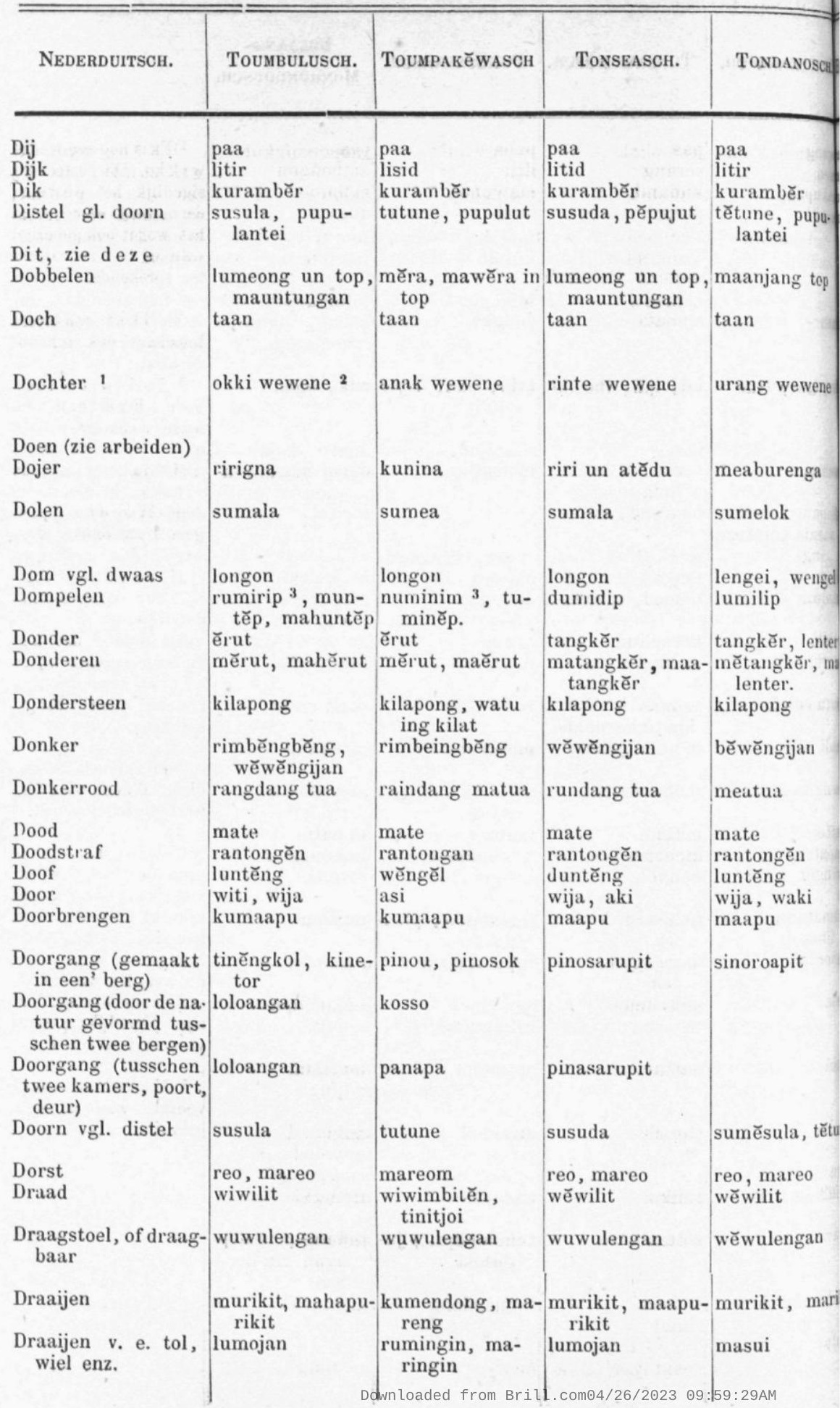




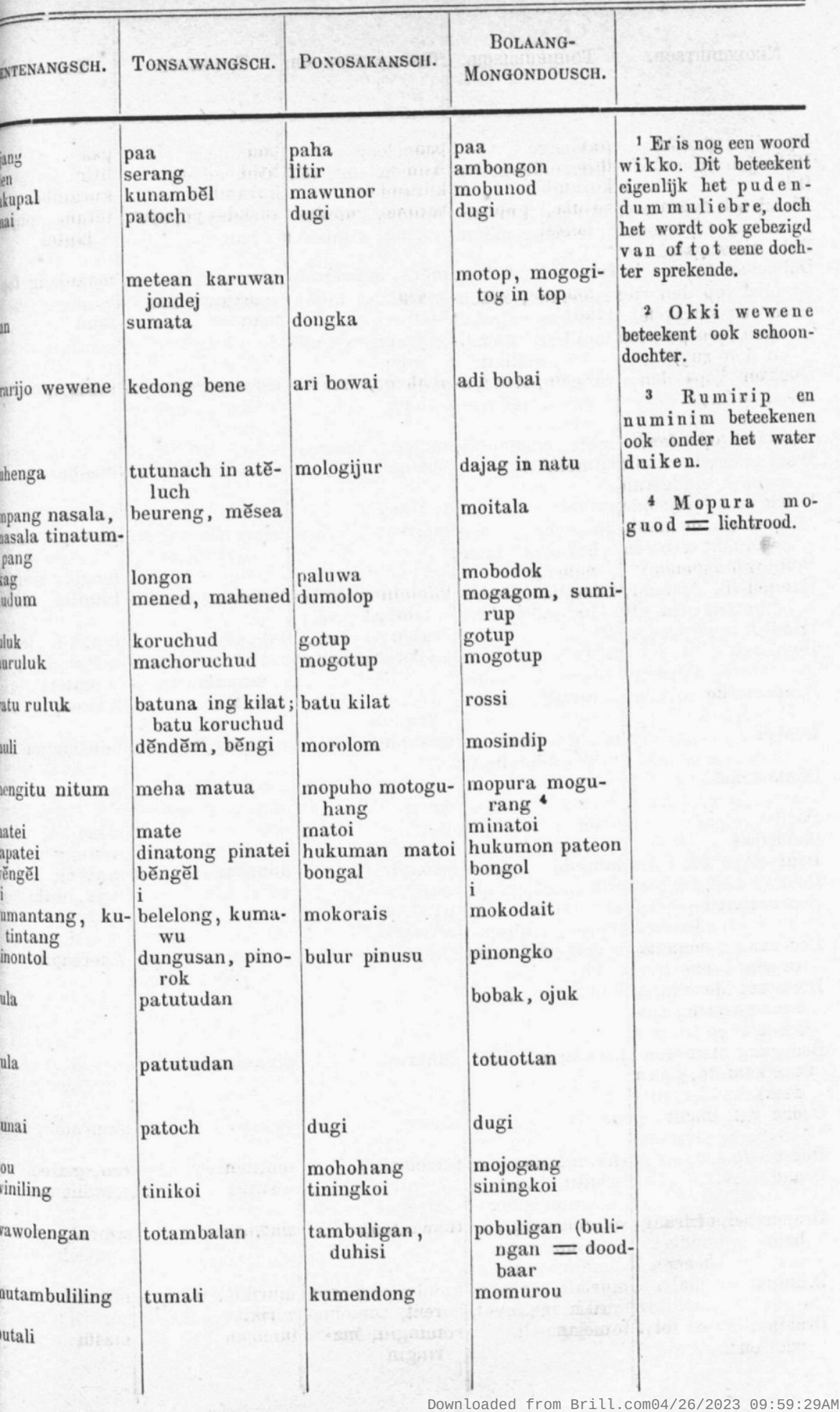




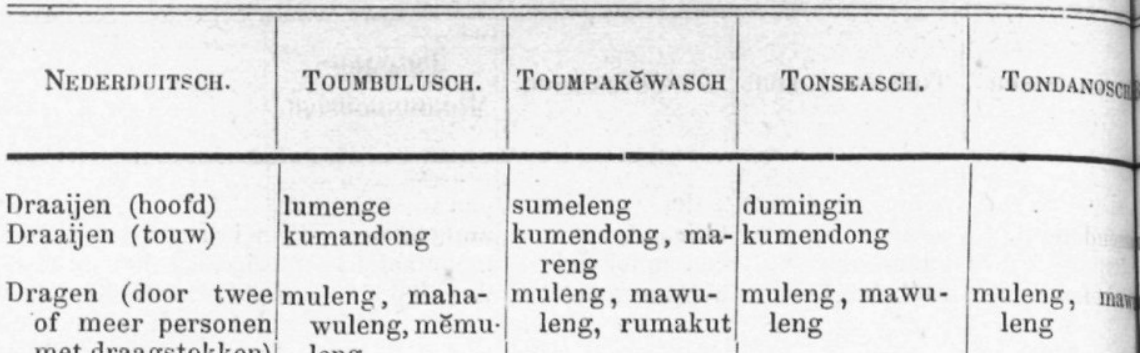
met draagstokken) leng

Dragen (op den rug rumakut, maha-marakut, mijo in een sangkolé) rakut, měrakut

rumakut, maha- sumangkolei

Dragen (een persoon lumikur, mahali-mijo, mawijo, mĕ- dumikud op den rug)

Dragen (op den schouder)

\section{kur, mělikur mijo}

masaan, mahapa- muleng, mawnsaan, měma- leng saan

Dragen (op den schouder, de vracht aan het einde van een stok hangende

Dragen (in de hand, kumeneng, ma-meiwei de vracht aan een hakeneng, mentouw hangende) geneng

Dragen (in de hand, kumulu, mahaku-kumulu (dit beof in den arm, als lu, mẽngulu bijl, houweel, mes)

Dragen (op den arm, rumawak, maha-kuměkěp of op de armen, rawak, měraals: een kind) wak

Dragen (onder den mingki, mahing- kumipit krom naar beneden $\mathrm{ki}$, měngingki hangenden arm)

Dragen (op de hand mopo, mahopo, mopo of handen)

Dragen (onder den mimpit, mahim-kumipit oksel, met den arm pit, měngimpit regt naar beneden)

Dragen (met een doek maror, mahawa-mawarat of touw schuins over den schouder, zoodat de vracht op de andere zijde hangt)

Dragen (met een mawei, mahawei, kumawit touw of doek over den schouder, zoodat de vracht op dezelfde zijde hangt) $\begin{gathered}\text { Dragen (goederen op } \\ \text { het hoofd) }\end{gathered}$
sumungsung, ma-tumeinteng
hasungsung,

Dragen (een kind op sumungsung, ma-tumeinteng beide schouders met de beenen langs den hals)

Dragen (de geplukte muwit, mahuwit, muwit, tumein- muwit padi in een korf měnguwit naar het tuinhuisje)

$$
\text { ror, měmaror }
$$

mĕngawei

hasungsung, měnungsung teng, měngkei saan wak mimpit

masaan. maapa-měsaan saan, mamamě:i, mapěti

měti, mapěti, měti

kenengĕn (pass.) gumege, mage makeneng měgege

kumudu, maaku-kumulu, maku du mẽngulu

rumawak, mara-rumawak, mar wak, měraw

kumalo, makal měngalo

mopo, maароро mopo, mapop měmopo

mimpit, maimpit mimpit, mahi pit, měngim

maror, (zelden slechts in gebruik) sumam mawei, maaw mĕngawei bět, maasambět

mawei, maahawei mawei, maaw měngawei

sumuun, maasuun

malelei Downloaded from Brilt 


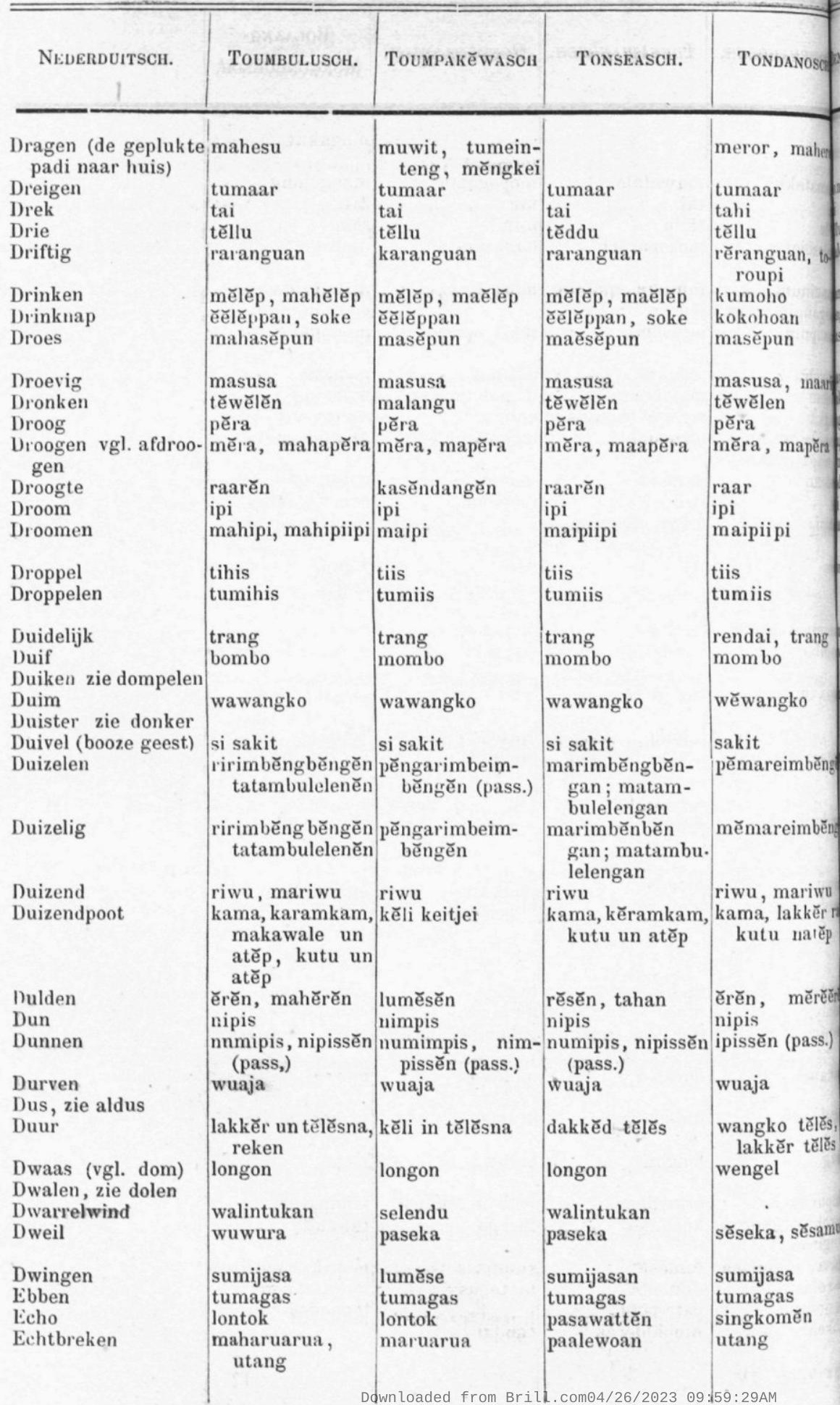




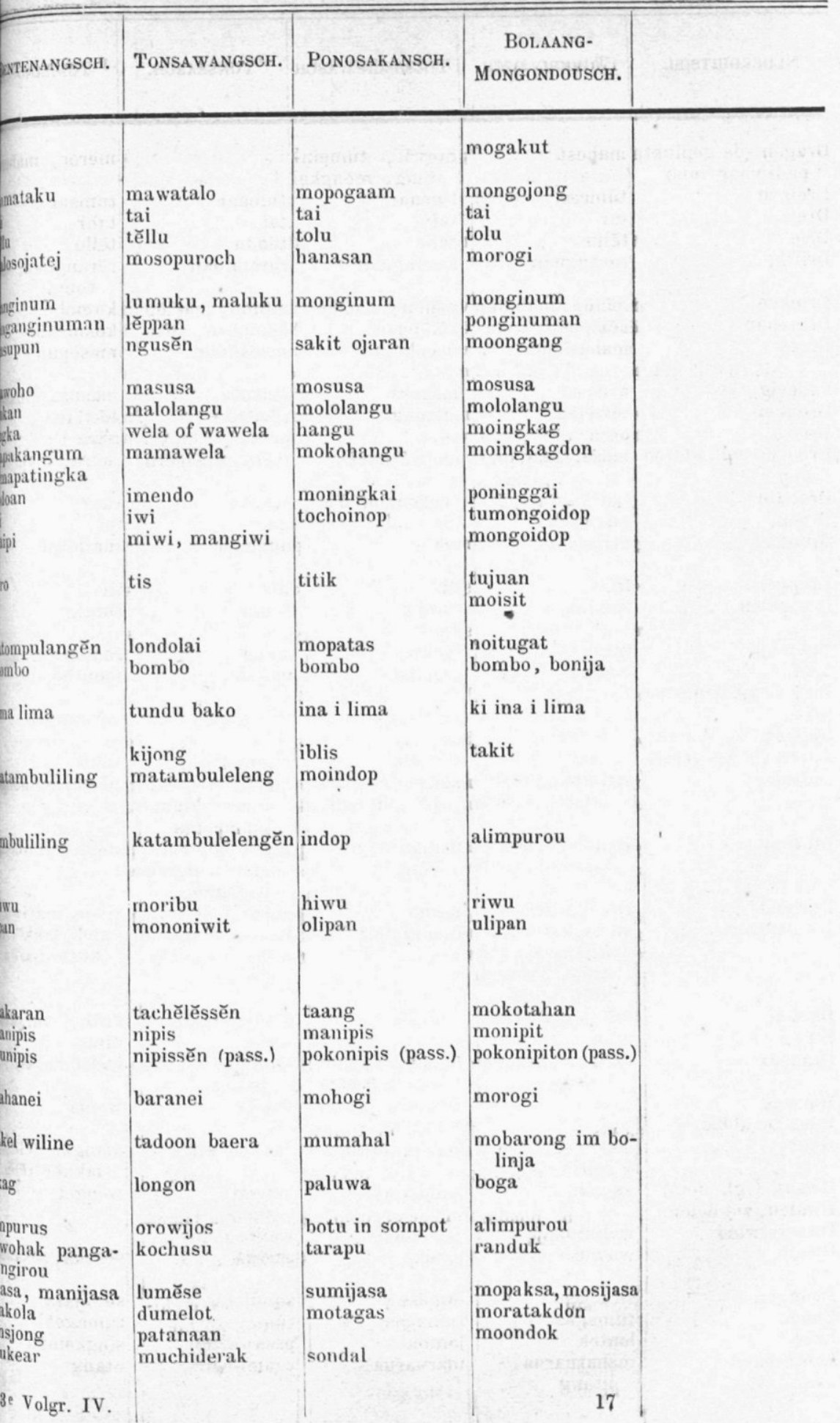




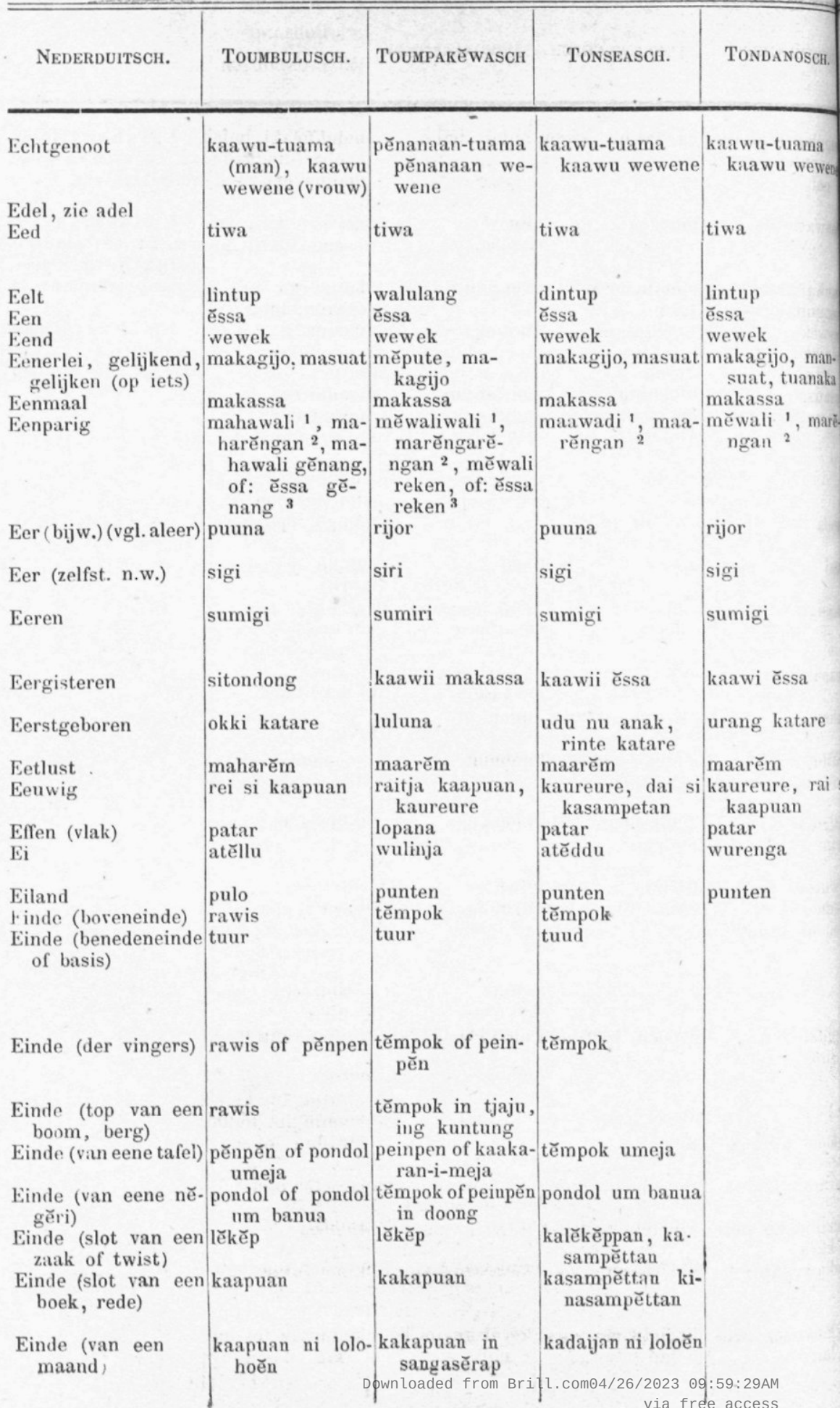




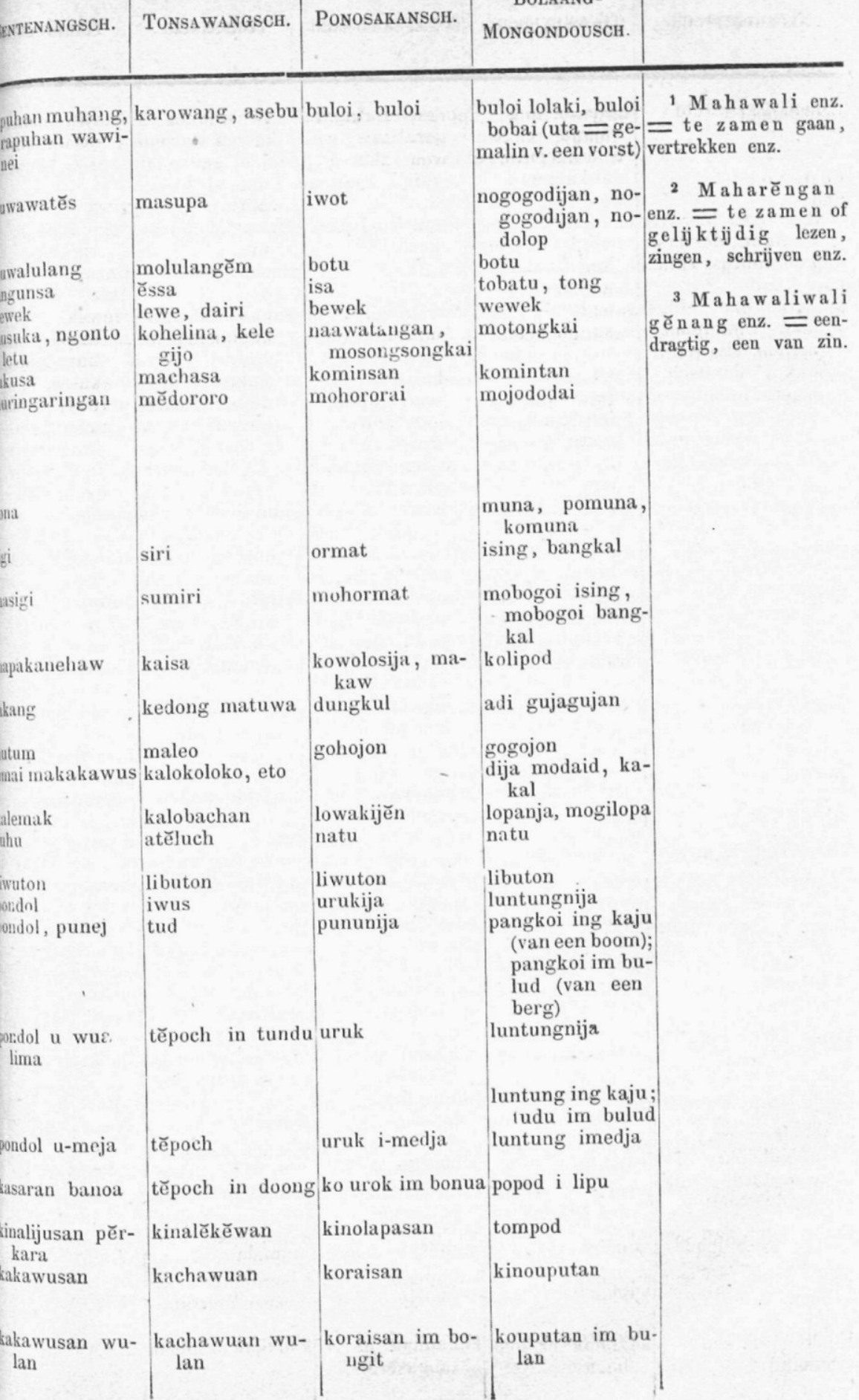




\begin{tabular}{|c|c|}
\hline NEDERDUITSCH. & Toumbulusch. \\
\hline $\begin{array}{l}\text { Einde der wereld } \\
\text { Eindeloos }\end{array}$ & $\begin{array}{l}\text { kaapuan ang } \\
\text { kaajahan } \\
\text { rei si akarran, rei } \\
\text { si kaapuan }\end{array}$ \\
\hline $\begin{array}{l}\text { Eklips (zie hierover } \\
\text { de Aant., die na de } \\
\text { woordenlijst zullen } \\
\text { volgen) } \\
\text { El. Hiervoor hebben } \\
\text { al de hier voorko- } \\
\text { mende dialecten } \\
\text { ons Hollandsch } \\
\text { woord. In het voor- } \\
\text { bijgaan geven wij } \\
\text { de lengtematen bij } \\
\text { de inlanders in } \\
\text { gebruik. }\end{array}$ & 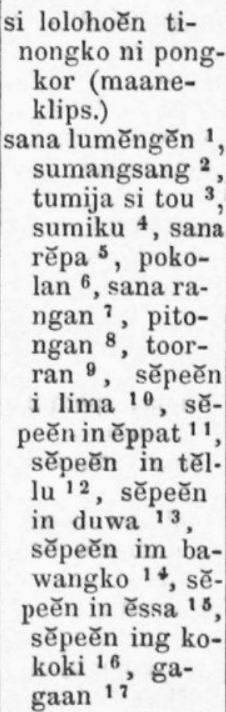 \\
\hline
\end{tabular}

Elf

En

Enkel (zelfst. n. w.)

Enkelring

Erf

Erfenis

Erfgenaam

Erg (ziek)

Erkennen

Erlangen

\section{Erven}

\section{Eten}

Eten (rijst, maïs, vruchten enz.)

Eten (gekookte of geroosterde maïs aan de steel)

Eten (verschillende toespijzen)

Eten (groenten)

Eten (vleesch- of vischnat)

\section{mapulu woĕssa}

wo, woan

wuku un-ae wěntěl

lessar

tulau

tulauan

raraan rěpět

makanau

makailěk

makailěk un tulau

tumikoho

kuman

rumuum

suměra

sumende

sumerop kakapuan ing kajombaan

i raitja akarran, dai si kaakadan; rai si kaapuan raitja kaapuan dai si kasam. pěttan

tinongko i pong-tinongko ni ru tinongko ni kor. mau

tumumběl 1, su-sana dumĕngan 1, luměngĕn ', ș maasa 2 (de tweede a ten halve uitspreken) tumija tou ${ }^{3}$, sitjum ${ }^{4}$, sanga rěpa ${ }^{5}$, sanga rangan ' pitongĕn ${ }^{8}$, pakon ${ }^{9}$, sĕpeĕn im palar ${ }^{10}$, sě. peẽn in é pat 11 sěpeěn in těllu 12 , sĕpeẽn in duwa ${ }^{13}$, sĕpeěn im bawangko ${ }^{14}$, sěpeěn in ěssa 15 , sěpeěn ing kalassing 16

\section{sangapulu wo} ěssa wo, wona wungkele wěntěl

lessar

tělauěn

tělauan

sumakit rěpēt

makatuus

makaere

makaere in tělauěn

tumitjoho

kuman

rumuum

s

snměra

sumende sumangsang 2 , tumea tou ${ }^{3}$, sumiku ${ }^{4}$, sana děpa ${ }^{5}$, tawi sana děpa ${ }^{6}$, sana raat ${ }^{2}$, pitongan ${ }^{8}$, sěpeěn un dima 10 , sĕpeěn un ěppat 11 , sĕpeěn un tĕddu ${ }^{12}$, sěpeěn un duwa ${ }^{13}$, sěpeěn um bawang. ko ${ }^{14}$, sěpeěn un ěssa 15 , kemasa ${ }^{2}$, sumi. $\mathrm{ku}^{4}$, sanga $\mathrm{r}$ : pa ${ }^{3}$, sanga rangan ', pitongan ${ }^{8}$, sêpeěn lima ${ }^{10}$, sěpeț in ěppat 11, peěn těllu $1:$ sěpeěn duwa sĕpeěn běwang ko ${ }^{14}$, sěpee ěssa ${ }^{15}$, sěpe: no oki ${ }^{16}, 8$ gaan 17

\section{akaan 17}

nongko
ramau

gaan 11
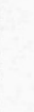

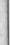




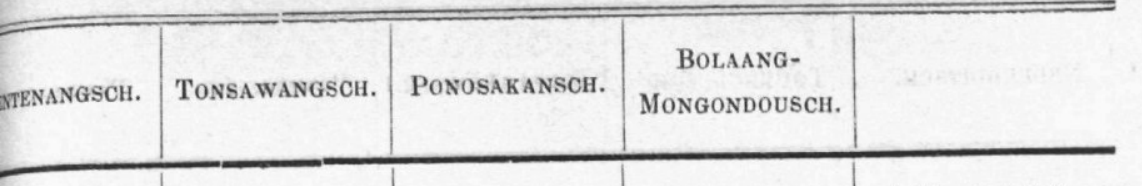

gwasan tana kachawuan ing kijamet kauchaan rungan

ppolain 1, ma-1 akarak ${ }^{2}$, sum. iku ${ }^{4}$, sun $\mathrm{pa}^{5}$, sanda${ }^{7}$, rangun asuan 8 , pukuin ${ }^{9}$, rupatĕn alěr 10 , rupaapa um bua ${ }^{11}$ rupatěn tẽllu am bua ${ }^{12}$, rutěn rambua ${ }^{13}$, rupatěn juma lima 14, rupaťn sumbua ${ }^{15}$, rupatěn kakindisai ${ }^{16}$, gabanggangěn 17

apulo sa

akulali

tas, singka

atal, bedeng

ggkuwa

pitingkuwaēn

auwa

akatjaja

umumpak

lutingkuwa

uman

umankan

languku

aminas

angussap

angijup sanguwulu basa

bo

bakujung

alak, ela

lisad

tẽlaun

toumachatělaun

dēpēt

mahilala

kumita, kumunita

machatělaun

kuman

kuman

kumau

monudak

monudak

maluku

kouputan ing ko. bajangan, dija kodaitan

tinukał i homa

ilijom in naga

Van het einde van het schouderblad.

2 Van het einde van den middelvinger tót midden op de borst.

3 Van het einde van den $\mathrm{m}$. vinger tot aan den andereu schouder.

+ Van het eiude van sono jangou ${ }^{7}$, tak $^{2}$, kopotasono jangou in $\operatorname{anan}^{3}$, sumiku ${ }^{\top}$ tundu ${ }^{8}$, pako- tongo jopa ${ }^{5}$, den $m$. vinger tot aan on ${ }^{9}$, dopot im tongo jangou ${ }^{7}$, den elleboog.

palar 10 , dopot in opat 11 , dopot in těllu ${ }^{12}$, dopot in duwa ${ }^{13}$, dopot ina $\mathrm{i}$ lima 14 , dopot in tundu 15 , dopot in tundu isikan ${ }^{10}$, sangkangon 1 ?

dija tuga tongo jangou 8 , pakon ${ }^{9}$, dojos im palad 10 , dojos in opat no bu

5 Een vadem.

6 Een vadem min

nga 11 , dojos in 7 Een span: d. i. van tolu no bunga 12 het uiterste des duims dojos in dea no tot aan het uiterste van bunga ${ }^{13}$, dojos den middelvinger. ing $\mathrm{ki}$ ina $\mathrm{i} \mathrm{li}$ ma 14 , dojos

8 Een span: d. i. van in tonouju 15, het uiterste des duims dojos in tondo i tot aan het niterste van sikan ${ }^{16}$, dojos den wijsvinger.

im palad mo-

lungkag 17

mopulo wo sa mopulo bo mita watu

wo

ninatai tijol

uoai tijol

ongowan

sundur

kosundur

paja

tumuos

mokorungkul

bo

bokulali

dolaag

pusaka

motakit pajadon

mokodungkul

mokodungkul

kompusaka

mongaan

mongaan

mongoko kinola

mokaan

mongaan

mokokob (eten oude mais) mo- enz.

ranut (eten jonge mais.

moseha

mokaan, monoja (eten visch)

moseha in suwap mokaan kong kujad

monginom ti- monginum kom wigija
9 De vuist met den duim in de hoogte, circa $\frac{1}{2}$ voet.

10 Vijf vingers breed, over het midden van den duim gemeten. S $\breve{\text { - }}$ pe ěn beteekent: wordt geklapt met de vlakke hand.

11 Vier vingers breed, over het midden der vingers gemeten.

12 Drie vingers breed, over het midden der vingers gemeten.

13 Twee vingers breed, over het midden

14 Een dnimbreed.

15 Een vinger (wijsvinger) breed.

16 Een pinkbreed.

17 Breedte der vijf vingers, doch geopend. 


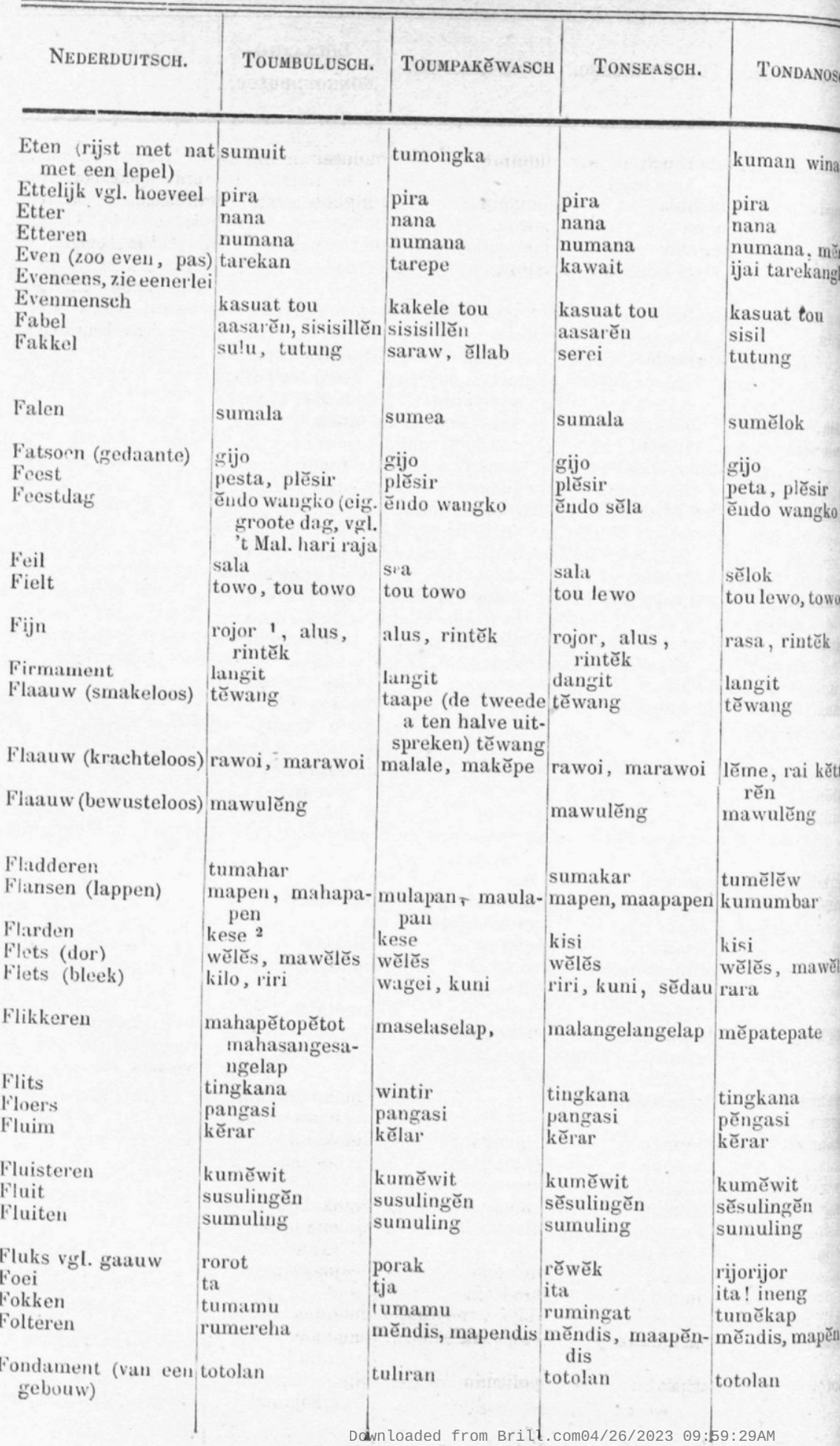




\begin{tabular}{|c|c|c|c|c|}
\hline Nederduitsch. & Toumbulusch. & TOUMPaKёWASch & TonsEasch. & TONDANOSC \\
\hline Fontein & kĕmbuan un dano & $\begin{array}{l}\text { palĕmbojan in } \\
\text { dano }\end{array}$ & $\begin{array}{c}\text { pakĕmbuan in } \\
\text { doud }\end{array}$ & $\begin{array}{l}\text { kĕmbuan dano } \\
\text { gagaran }\end{array}$ \\
\hline Foppen & muwak, mauwak & muwak, mauwak 1 & muwak, mauwak & muwak, maury \\
\hline Forsch (sterk) & $\begin{array}{l}\text { kěttěrĕn, kěttěr, } \\
\text { ente } \\
\text { siga }\end{array}$ & kěttěr, kěttěrěn & $\begin{array}{l}\text { kěttěd, kěttěd- } \\
\text { děn } \\
\text { siga }\end{array}$ & kěttěrěn, ente \\
\hline $\begin{array}{l}\text { Fort } \\
\text { Forpierd) }\end{array}$ & $\mid \begin{array}{l}\text { siga } \\
\text { kota }\end{array}$ & \begin{tabular}{l|l} 
takte \\
kota
\end{tabular} & $\begin{array}{l}\text { siga } \\
\text { kota }\end{array}$ & kota \\
\hline Fortuin & $\begin{array}{l}\text { kamang leos, } \\
\text { untung }\end{array}$ & kamang, untung b & $\begin{array}{l}\text { kamang leos, } \\
\text { untung }\end{array}$ & kamang, untur \\
\hline $\begin{array}{l}\text { Fout (zie feil) } \\
\text { Fraai }\end{array}$ & wangun, gijo leos & loor & wangun & wangun, gijo \\
\hline $\begin{array}{l}\text { Franje } \\
\text { Fret (zie boor) }\end{array}$ & djaladjala & pranji & djaladjala & \\
\hline Frisch (vgl. goed) & rate leos & uting sama & date leos & geger leos \\
\hline Frons & kulěn & linsěn & kunděl, dinsěn & kulěn, linsěn \\
\hline Fronsen & kumulěn & luminsēn & $\begin{array}{l}\text { kumundēl, du- } \\
\text { minsěn }\end{array}$ & kumulěn \\
\hline Fruit & $\begin{array}{l}\text { kakanněn, wua } \\
\text { ung kai }\end{array}$ & $\begin{array}{l}\text { kakaněn, wua in } \\
\text { tjaju }\end{array}$ & $\begin{array}{l}\text { kěkanněn, wua } \\
\text { ing kaju }\end{array}$ & $\begin{array}{l}\text { kekaaněn, wus } \\
\text { ung kai }\end{array}$ \\
\hline Fuik & $\begin{array}{c}\text { kalasei, wuwu, } \\
\text { tingkĕp }\end{array}$ & $\begin{array}{c}\text { kalasei, wuwu, } \\
\text { kolombuan }\end{array}$ & kalasei, tĕtingkěp & kělasei \\
\hline $\begin{array}{l}\text { Gaaf (vgl. goed) } \\
\text { Gaan }\end{array}$ & leos & sama & leos & leos \\
\hline Gaar (vgl. koken) & lutu & $\begin{array}{l}\text { mange } \\
\text { roro }\end{array}$ & $\begin{array}{l}\text { mange } \\
\text { dutu }\end{array}$ & $\begin{array}{l}\text { mae } \\
\text { lutu }\end{array}$ \\
\hline Gaard & $\begin{array}{l}\text { rerehen, tatanĕ- } \\
\text { měn }\end{array}$ & patinaněman & tatĕněměn & $\begin{array}{l}\text { tinaněm, těta- } \\
\text { něměn }\end{array}$ \\
\hline Gaarne & mahapaapaar & masalesale & maapaadpaad & mêpaapaar \\
\hline Gaauw (vgl. fluks) & ruměwĕrěwěk & moraporak & $\begin{array}{l}\text { ruměwěrĕwěk, } \\
\text { rae }\end{array}$ & siga, marij \\
\hline Gal .. & apěru & apĕru & apědu & pĕru \\
\hline $\begin{array}{l}\text { Galerij } \\
\text { Galg }\end{array}$ & kandarijan & & kěndarija & \\
\hline Galopperen & $\begin{array}{l}\text { kumara, kumom- } \\
\text { po }\end{array}$ & $\begin{array}{l}\text { kaloppeer, repet } \\
\text { tumintjas, tu- } \\
\text { meron }\end{array}$ & $\begin{array}{l}\text { kumompo, tu- } \\
\text { meitei }\end{array}$ & tumingkas \\
\hline Gang (van menschen) & kěkeang & rumambun & kěkelang & kapakalang \\
\hline Gansch & peleng, timomor & waja, timomor & waja, timomor & waja, timomor \\
\hline Gapen & ngumanga & ngumanga & ngumanga & ngumanga \\
\hline $\begin{array}{l}\text { Garen (zie draad) } \\
\text { Garnaal }\end{array}$ & & & & \\
\hline $\begin{array}{l}\text { Garnaal } \\
\text { Garstig }\end{array}$ & $\begin{array}{l}\text { Sapun } \\
\text { nanaman }\end{array}$ & $\begin{array}{l}\text { ulang } \\
\text { lumiitj }\end{array}$ & $\begin{array}{l}\text { sapun } \\
\text { nanaman }\end{array}$ & $\begin{array}{l}\text { Sapun } \\
\text { liik }\end{array}$ \\
\hline Gast & sakei & sakei & sakei & sakei \\
\hline Gastvrij & $\begin{array}{c}\text { sumakei }{ }^{3} \text { maka- } \\
\text { sakei }\end{array}$ & $\begin{array}{c}\text { sumakei, maka- } \\
\text { sakei }\end{array}$ & $\begin{array}{l}\text { sumakei maka- } \\
\text { sakei }\end{array}$ & měsakei \\
\hline $\begin{array}{l}\text { Gebed } \\
\text { Gebeente }\end{array}$ & $\begin{array}{l}\text { aalei } \\
\text { ruhi }\end{array}$ & $\begin{array}{l}\text { pěngangilěk } \\
\text { rui. }\end{array}$ & $\begin{array}{l}\text { makuwe } \\
\text { dui }\end{array}$ & $\begin{array}{l}\text { makiwehe } \\
\text { rui }\end{array}$ \\
\hline $\begin{array}{l}\text { Gebergte (zie berg) } \\
\text { Gebeuren }\end{array}$ & muali, mamuali & muali, mamuali & muali, mamuali & muali, mam \\
\hline
\end{tabular}




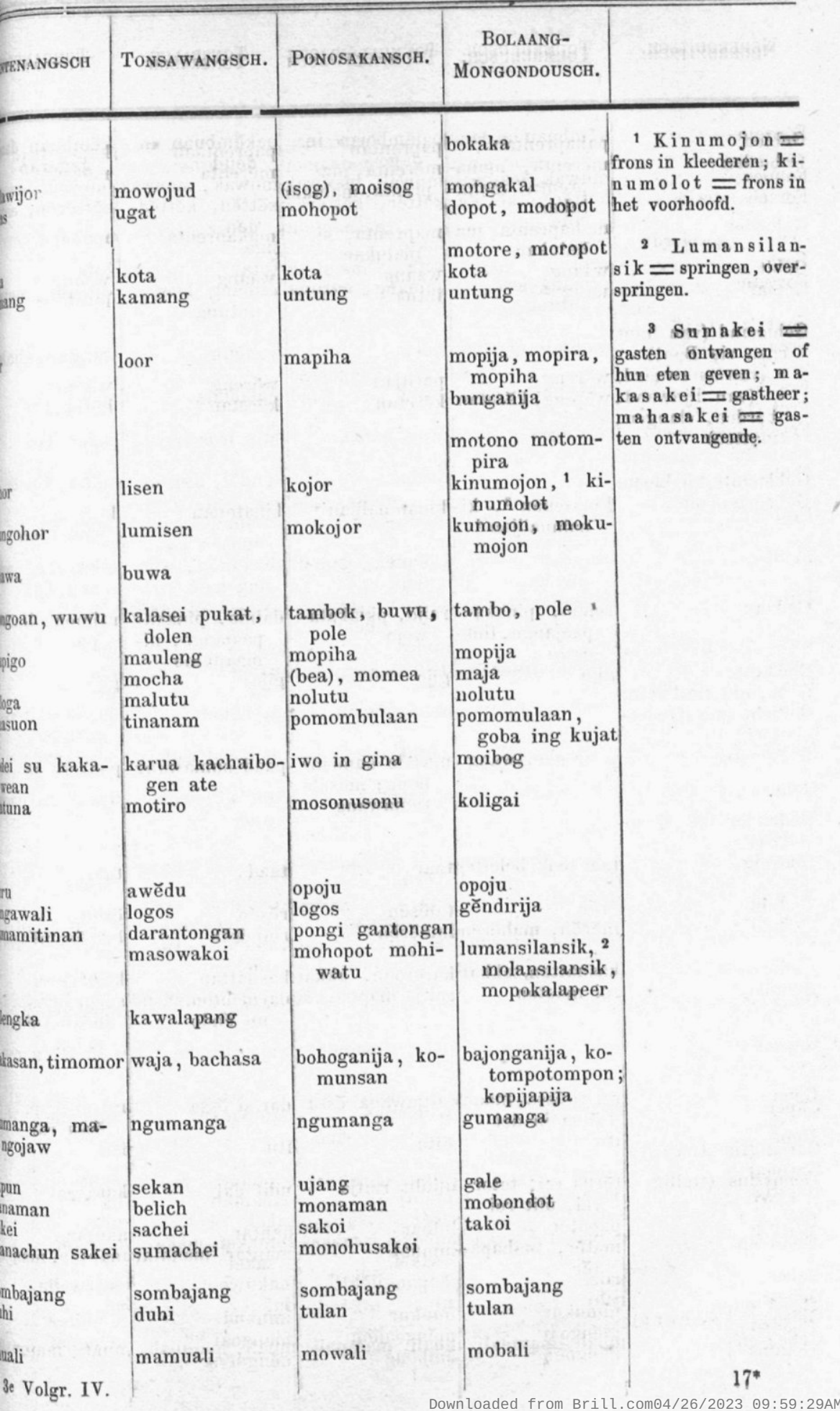




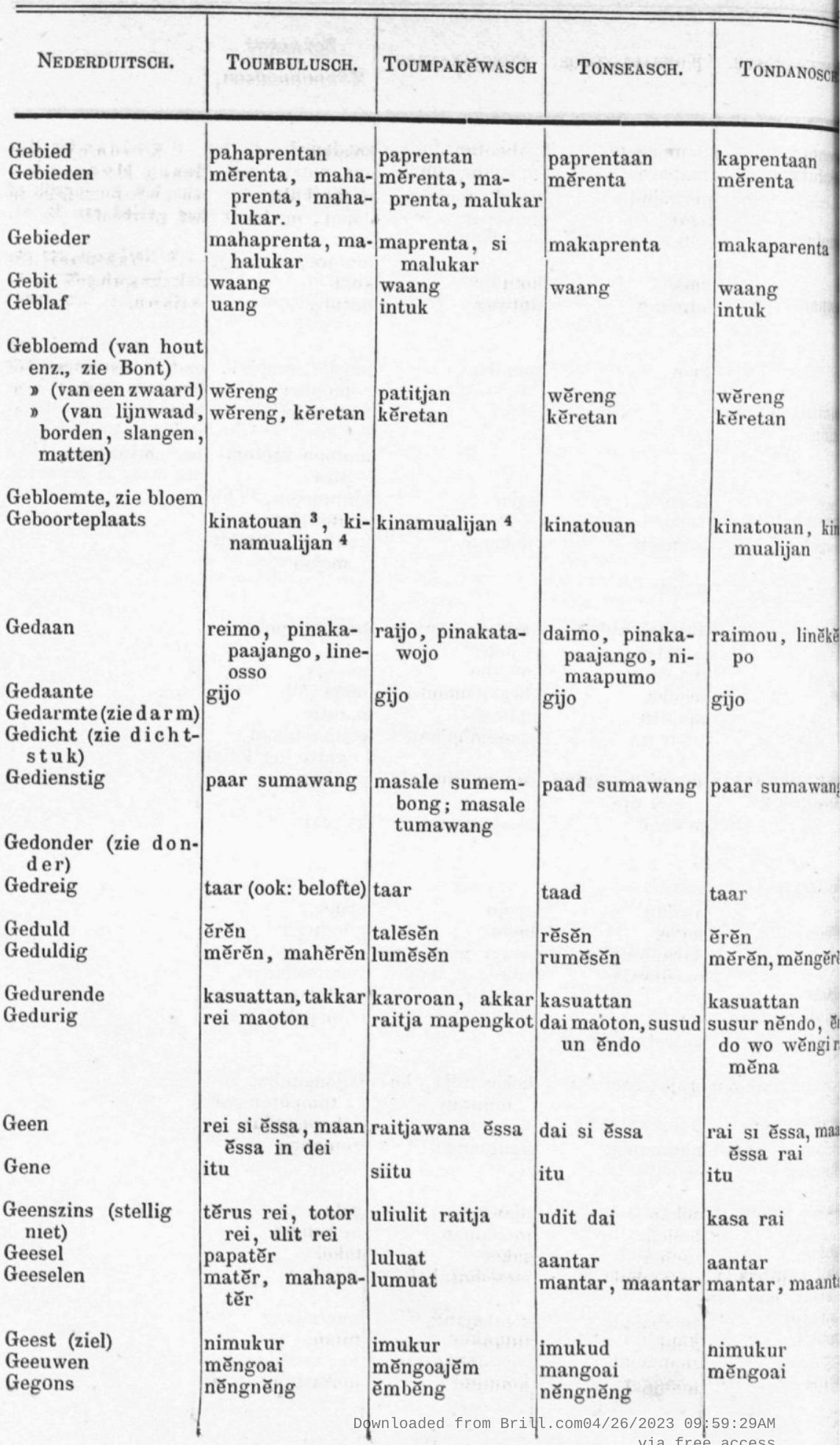




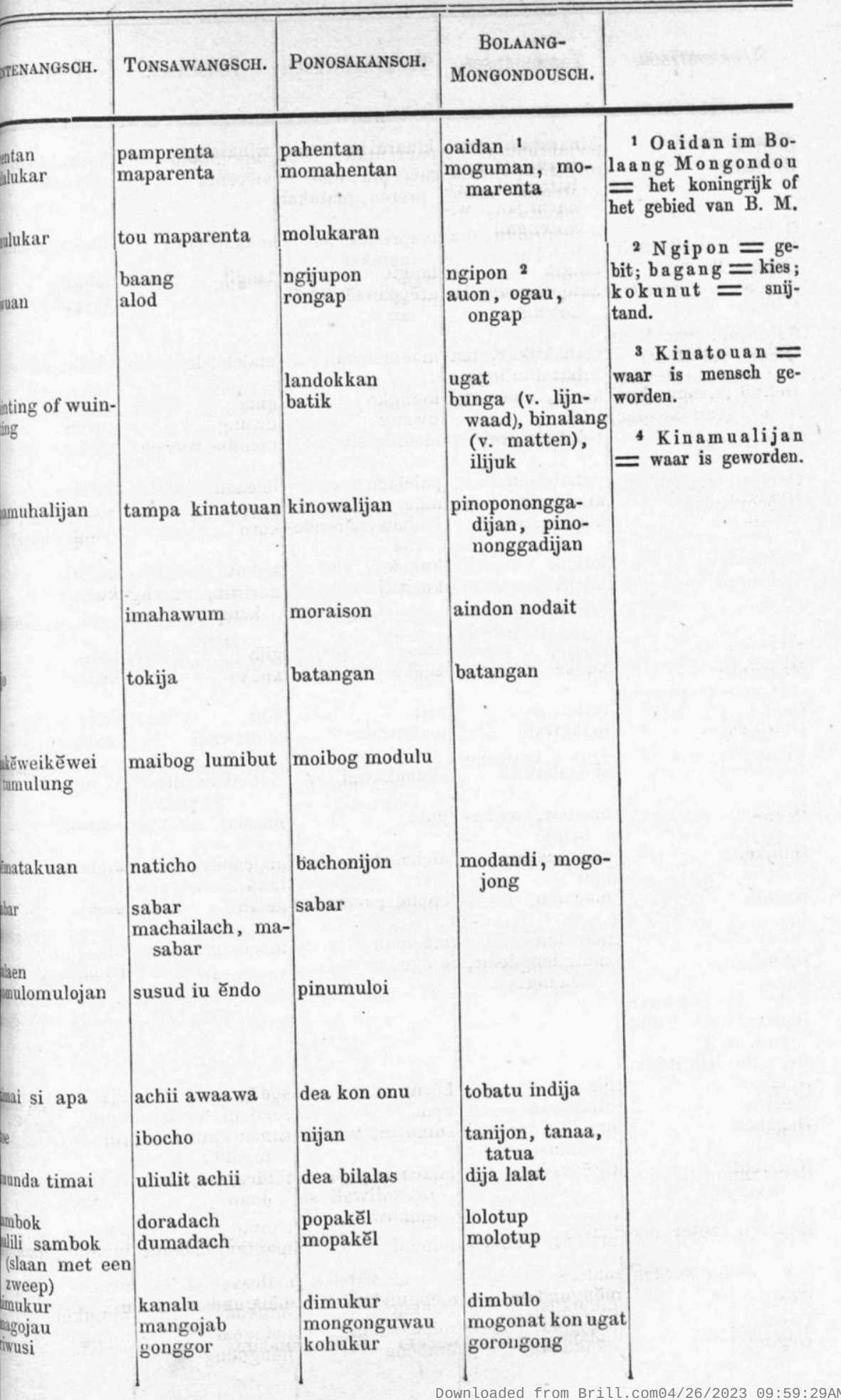




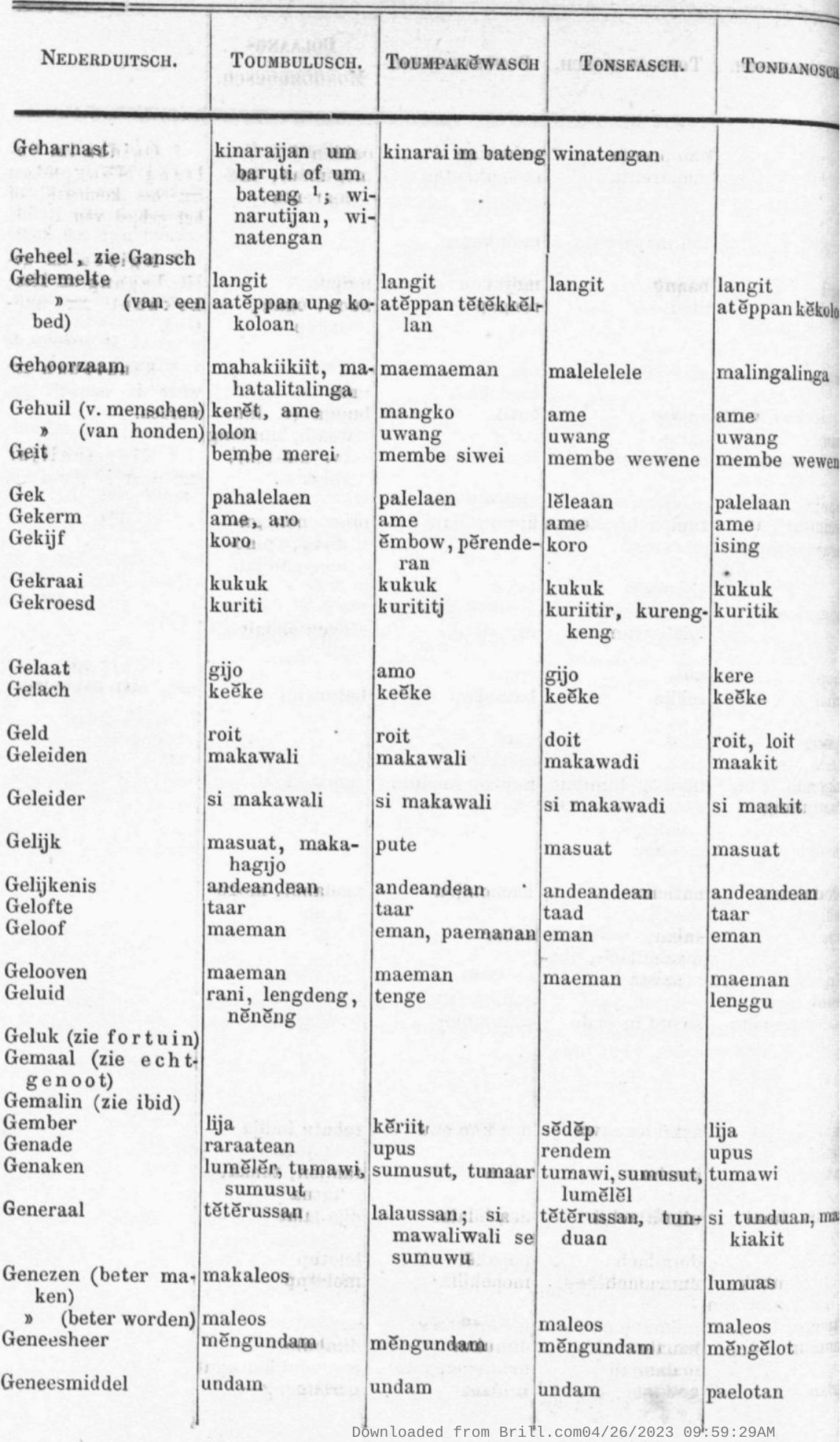


abe wawinei

puja

ingisan

sasuantingi

inggolong

tup

pang

unde, mangonde

tangonde

gusuka

teandean

ndijan

man

žngeman

truntung

agilir

tangege

owahani

apigo

angangundam

undam
Tonsawangsch. Ponosakansch.

mogibateng ${ }^{2}$, mogibolulang

BOLAANG-

Mongondousch.

$1 \mathrm{~K}$ inaraijan um baruti $=$ is aangetrokken geworden een koperen harnas, of is gekleed met een koperen harnas; wateng $=$ harnas van vel van de antilope of van touw. De w van wateng en waruti is wegens de voorgaande $\mathrm{m}$ in b veranderd.

2 Bateng $=$ har-

ojau

uang

uang

uang

bembe bowai

bembe bene

palelaan

kaei

pěweroan

namangan

ijar

mohowintjing

kijohoch

kalu, makalu

kuku

wownlongkong

amo
keěke
doit

mali

pachlalasan, ma-mototakin

chawali

mokele

andeandean

randijan

eman, pahema nan

maeman

tengech

pogos

kosing

doit:

motakin

bembe kobakja

lolongonan

ojau

morobibig

kokuu

nas van gevloehten touw; bolulang $=$ harnas von het vel der antilope.

3 Korengkeng $=$ geluid, fijn geluid;

buok nobulong. gorongong $=$ dof kong (gekroesd geluid.

\begin{tabular}{l|rl} 
haar) & 4 Wolijan, pries- \\
pogot & ter; diúvelbezweèrder.
\end{tabular}

kosing

doit

mogatod

motongkai

mangalenja

andeandean

randijan

iman

moiman

sahingsing

iman

mongiman

korengkeng ${ }^{3}$, goter; diuivelbezweerder. lija

chakes

surnusut

pachalalasĕn

mawamauleng

měmauleng

machawachun-

dam

undam rongong

$$
\text { n }
$$

mojuman

kotawi

mokorijuw

moghowi

mokopiha

nokopihaan

undam

luja

mokotanob

monompija
nopija
wolijan
undam 


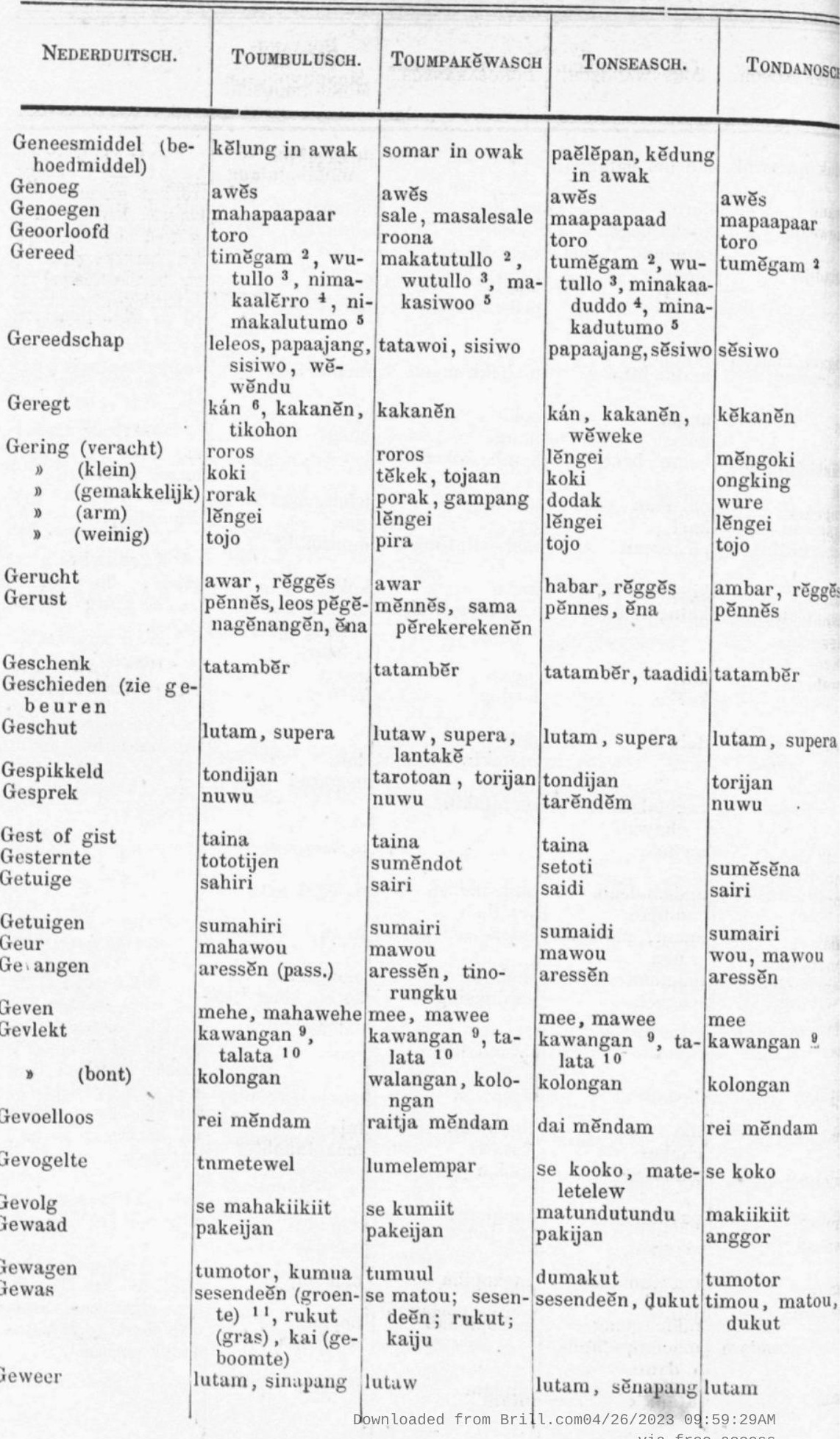


Deze Woordenlijst wordt in volgende afleveringen voortgezet. 